\title{
PL-4
}

\section{Novel Functionalized Tire Elastomers via New Functional Monomers}
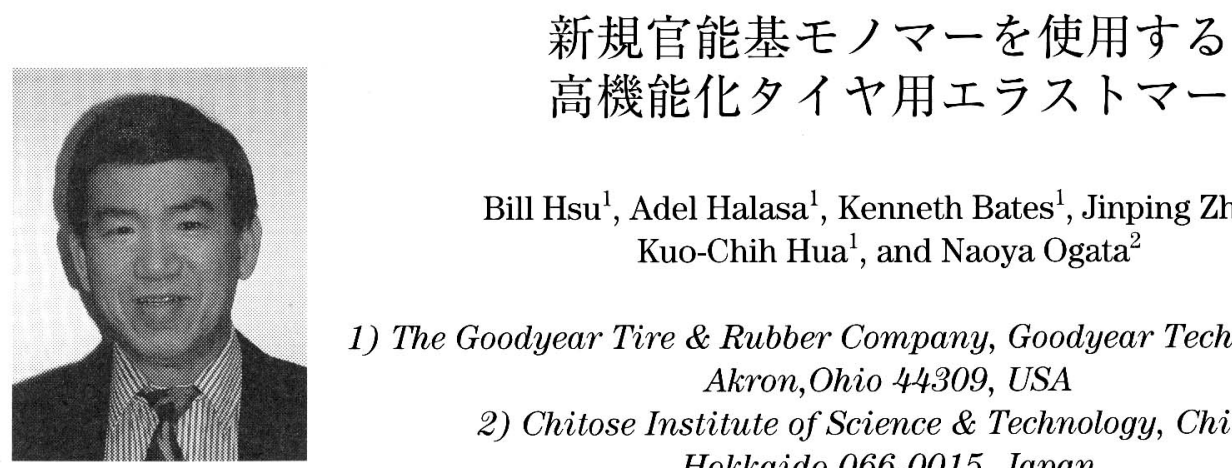

Bill $\mathrm{Hsu}^{1}$, Adel Halasa ${ }^{1}$, Kenneth Bates ${ }^{1}$, Jinping Zhou $^{1}$, Kuo-Chih Hua ${ }^{1}$, and Naoya Ogata ${ }^{2}$

1) The Goodyear Tire \& Rubber Company, Goodyear Technical Center, Akron, Ohio 44309, USA

2) Chitose Institute of Science \& Technology, Chitose, Hokkaido 066-0015, Japan

E-mail:wlhsu@goodyear.com

Bill Hsu

Dr. Bill Hsu received his Ph.D. in organometallic chemistry in 1980 from the University of Louisville. After spending one and a half years as a postdoctoral fellow on metal cluster chemistry at the Ohio State University, he joined the Corporate Research Division of the Goodyear Tire and Rubber Company in 1982.

In his earlier years at Goodyear, Dr. Hsu was involved in all aspects of catalytic research related to rubber monomer preparation including hydroformylation, dehydration, Fischer-Tropsch, and hydrogenation. In 1985, he started his polymerization career making diene homopolymers and their copolymers with styrene for tire applications under the direction of Dr. Adel Halasa. His expertise is in the area of tailor-making specialty polymers to improve tire performance using both Anionic and Ziegler-Natta polymerization techniques.

Dr. Hsu is currently an R \& D Associate in the Compound technology of the Material Development Department. He became a distinguished corporate inventor in 1997 and was elected as inventor of the year in 2000. He was honored as a member of the $100 \mathrm{club}$ (holding 100+ US patents) in 2005. Dr. Hsu currently has 107 US Patents and more than 50 referenced publications in the area of organomeallic chemistry, inorganic chemistry, polymer chemistry and tire elastomers. He has presented several seminars at universities and scientific meetings, and also chaired several scientific meetings on tire polymers.

\begin{abstract}
Hydrocarbon elastomers bearing polar functional groups at their chain ends or at both chain ends can greatly reduce the hysteresis of a tire compound and thus improve rolling resistance and fuel economy. These functional elastomers can be easily prepared via living anionic polymerization techniques. However, to prepare an elastomer with more than two functional groups in the same polymer chain, especially along the polymer backbone, a more elaborate and costly process is normally required. To facilitate the in-chain functionalization of tire elastomers, we have developed a series of new styrenic and Éø-methyl styrenic monomers containing various amine functional groups starting from relatively inexpensive divinylbenzene or diisopropenylbenzene. These functional monomers allow one to prepare novel functionalized tire elastomers containing any number of amine functional groups at any location within the polymer chain via anionic co-polymerization with any conjugated diene or styrene monomer. More importantly, polymerization can be carried out over a wide temperature range, even at the elevated temperatures normally used for commercial production of tire elastomers. The preparation of these new functional monomers and their co-polymerization with diene monomers will be presented. The physical properties of these novel functionalized polymers will be compared to their conventionally prepared counterparts in carbon black and silica filled compounds.
\end{abstract}

片末端もしくは両末端に官能基を有する炭化水素系エラストマーは夕イヤ組成物のヒステリシス損失を大きく低下させ, これにより転がり抵抗や燃費性が改良される。これらの機能性エラストマーはリビングアニオン重合技術で容易に製造で きる. しかしながら，一本の高分子鎖中に 2 個以上の官能基をもつエラストマー, 特に高分子鎖の内部にもつ場合は非常 に複雑で高コストとなるプロセスが通常必要になってくる．タイヤ用エラストマーの分子鎖中への官能基導入のために, 我々は比較的安価なジビニルベンゼンやジイソプロペニルベンゼンを原料としたアミノ基含有スチレン系モノマーを開発 
した．これらの官能基含有モノマーを特定のジエンやスチレンとアニオン重合することによって，分子鎖の特定の位置に 任意の数のアミノ基をもつタイヤ用エラストマーを製造できる.さらに重要なことは，このモノマーは市販のタイヤ用エ ラストマーを製造する昇温重合のような広い温度範囲でも重合できる。これらの官能基含有モノマーの合成とジエンモノ マーとの共重合について報告する. 高機能化ポリマーの物性はカーボンブラックとシリカの両配合で, 従来品と比較して 評価する.

\section{Introduction}

There is a never-ending demand to improve the fuel economy of automobiles. In light of the sharp rise in the cost of fuel over the last few years, the urgency for both automobile producers and consumers to find ways of cutting fuel consumption has increased. Reducing vehicle weight, improving vehicle aerodynamics, and minimizing the rolling resistance of the tires remain valid approaches to improve fuel economy without sacrificing vehicle safety.

It is well known that reductions in tire rolling resistance improve fuel economy. It has also been established that the hysteresis of the tread component of the tire construction plays the largest role in determining tire rolling resistance [1,2], especially for truck tires [2]. Tread hysteresis is generally the result of (1) carbon black networking (or more generally, filler-filler interaction), since the breakdown and reformation of filler networks following deformation and recovery consumes energy, (2) segmental friction of the polymer chains, and (3) dangling polymer chain ends. Hysteresis loss is greatly increased if there are too many unattached, or dangling, polymer chain ends as is normally observed when highly branched or low molecular weight polymers are utilized. Although chain end concentration can be easily reduced by increasing the molecular weight of the polymer, this also adversely affects the processability of the tread compound.

Numerous reports [3-15] published in the last two decades have shown the most effective means of reducing hysteresis is to increase the interaction between the polymer chain ends and the filler, including carbon black and/or silica fillers, through chain-end modification using polar functional groups. This improves hysteresis not only due to a reduction of free chain ends in the polymer network but also the improvement in polymer-filler interaction which results in better filler dispersion and hence reduces fillerfiller networking or the Payne effect [16]. Among these chemical modifications of polymer chain ends, Michler's ketone (4,4'-bis(diethylamino) benzophenone) [3,4] and chain-end coupling with tin tetrachloride [5,6] seemed to provide the most noticeable reduction in hysteresis for carbon black filled compounds. Later, it was found that other nitrogen or tin containing functional groups, such as NMP (N-methylpyrrolidone), heterocyclic amines (such as pyrrolidine, hexamethylenimine) $[8,15]$, trialkyltin [17] also exhibited significant benefits in reducing the hysteresis of carbon black reinforced compounds. It appears that carbon black has special affinity towards either nitrogen or tin compounds.

With the development of amine functionalized lithium initiators [ 8,15,18-21] and tin-lithium initiators [17] in the early 1990's, quantitative chain-end functionalization at the initiating $(\alpha)$ chain end of the polymer became possible. A similar improvement in rolling resistance was obtained with front end $(\alpha)$ functionalized polymers and their terminal-end $(\omega)$ functionalized counterparts. Additionally, the live (or active) carbanionic propagating polymeric species initiated by functional initiators could be further functionalized at the terminal $(\omega)$ chain end by terminating with appropriate amine or tin containing electrophiles (e. g., alkyl tin chloride or tin tetrachloride coupling agents) [20,21] to form $\alpha, \omega$ - difunctionalized polymers. These $\alpha, \omega$-difunctionalized (telechelic) polymers exhibited an even greater reduction of hysteresis compared to either $\alpha$-or $\omega$ - monofunctional polymers [22] in carbon black filled compounds. Although telechelic difunctionalized polymers can be prepared using dilithium initiators [23 - 27], only homo-telechelic (same functional groups on both chain ends) can be formed in this manner. In addition, the stability and limited non-polar solvent solubility of these dilithium initiators may hamper their industrial use for making functionalized polymers. The $\alpha, \omega$ difunctionalized polymers can also be made using linking agents (e.g., ester, ketone, dialkyldichloro tin or silicon, etc) combined with functionalized initiators; however, again, only the homo-telechelic polymers can be prepared.

Since hysteresis can be reduced by using $\alpha-\omega$ - chain end functionalized polymers, it is reasonable to wonder whether compound hysteresis can be reduced further if additional functional groups are incorporated into the polymer backbones. When both chain ends are attached to carbon black, a substantial reduction in hysteresis is obtained; however, the compound viscosity is also significantly increased [28]. So, now the question is - will both hysteresis and compound viscosity be reduced if the functional groups are located in the polymer backbones? Even though it is well known that chain-end functionalization is perhaps the best approach to reduce the hysteresis, it is interesting to consider how in-chain functionalized polymers affect filler - filler interaction and hysteresis in combination with compound processability.

The use of precipitated silica fillers with silane coupling agents in passenger tire treads has been reported [29]. In fact, compared to carbon black, significant tire performance improvement in rolling resistance and wet grip can be achieved simultaneously. However, silica compounds are still harder to process compared to carbon black filled compounds. This is due to hydrogen bonding in surface silanol groups, which form strong silica silica interactions. Once the silica network structure is formed, compound viscosity increases. To overcome this, a significant amount of silane coupling agents, such as bis-3-triethoxypropyltetrasulfide (TESPT) or bis-3-triethoxypropyldisulfide (TESPD) is required. In additional to the added cost of using expensive silane coupling agents, ethanol generated from the reaction between the silane coupling agents and the silanol groups on silica surface may cause problems related to VOC regulations. Furthermore, even with the use of silane coupling agents, unacceptable mixing with silica still exists for some polymers. This may be attributed to the lack of affinity between the non-polar rubber and the polar silica. To improve compatibility with silica, the polarity of non-polar hydrocarbon polymers has to be increased to enhance its affinity to silica. The most apparent way is to add polar functional groups to the polymers [30]. These functional groups should readily react with the silica surface via either chemical reaction or physical adsorption, such as hydrogen bonding with the silanol of the silica surface. It is well documented that alkoxy moieties of silane [31-32] or alkoxysilyl functionalized polymers [10] react chemically with the surface silanol groups to prevent the agglomeration of silica particles and 
improve processability. Although amines can not react with silanol to form siloxane, there are reports [ 12, 13, 33-35] showing that amine functionalized polymers also modify the silica surface and result in reduced hysteresis of the silica compounds. In fact, by the magnitude of a characteristic infrared silanol band shift, Wagner [36] observed that the strongest interactions with silica occur with amines. Wagner's observation was indeed confirmed by the fact that a tertiary amine has been successfully used as a wetting agent to improve both processability and rolling resistance of silica compounds [37].

By chain-end functionalization technique, a maximum of two polar functional groups can be incorporated into each polymer chain using standard anionic polymerization techniques, which is not enough to wet (react or adsorb) the extremely hydrophilic silica surface and improve its dispersion in highly filled compounds. One practical solution to increase the concentration of functionality on the polymer is to utilize an emulsion process to copolymerize functional monomers [33,34] with conjugated diene and vinyl aromatic monomers. However, anionically produced solution polymers are generally preferred for use in tires since they offer microstructural control and significantly reduced molecular branching. Both properties are key factors in balancing the wet grip and rolling resistance of tires.

A second approach to increase the concentration of functional groups is to chemically modify the backbones of a lithium polymer. Post backbone modification can be carried out by epoxidation, hydrosilylation [38,39], metallation/grafting [40] or other methods. Backbone functionalized solution SBRs containing up to 5\% of either hydroxy [41] or carboxy [42] functional groups have also been reported recently. Although the concentration of functional group can be substantially increased via post modification, it is also realized that any modification involving additional reaction steps will result in higher material cost.

It seems that the most practical way to increase the functional group concentration of a tire polymer is to copolymerize functional monomers with conjugated diene and vinyl aromatic monomers using standard anionic techniques. Furthermore, the functional monomer has to be itself inexpensive. From the foregoing discussion, it is apparent that amine functional groups can reduce hysteresis in both carbon black and silica filled compounds. It is also clear that increasing the concentration of functional groups beyond two per polymer chain may be also beneficial for silica filled compounds as more of the polar silica surface would be wetted to provide improvements in processability, hysteresis, and possible reduction in silane coupling agents.

Starting from the relatively low cost divinylbenzene or diisopropenylbenzene, a series of styrenic monomers containing various cyclic amine functional groups were prepared and investigated. Since amine functionalized styrenic monomers [43] prepared from a more expensive vinylbenzyl chloride and also amine functionalized isoprene monomers [44-46] have been discussed in the literature, polymers were synthesized from these monomers as well and compared in compound studies.

One of the advantages of in-chain functionalization using functional monomers is the ease of varying the location and the concentration of functional groups as these two parameters may have different optimal levels for carbon black and silica compounds in yielding optimum benefits. The objective of this study was to prepare functionalized polymers with functional group location/concentration optimized for specific compound properties for either carbon black or silica fillers.

\section{Experimental}

The monomers 1,3-butadiene, isoprene, and styrene were purified and dried as described previously [47]. TMEDA (N,N,N',N'-tetramethylethylenediamine), purchased from Aldrich, was distilled from calcium hydride prior to use. Potassium t-amylate (KOAm) and potassium 3,7-dimethyl-3octanoxide (KDMO), in hexane solution, were purchased from Callery Chem. Co., Pittsburgh, PA. They were dried over sodium or potassium metals, respectively. Pyrrolidine, piperidine, hexamethyleneimine (HMI), morpholine, 2,3-dibromopropene, and vinyl magnesium bromide (in THF solution) were obtained from Aldrich and used directly without further purification. Vinylbenzyl chloride (VBC), containing a mixture of 58:42 3and 4-VBC as determined by GC, was purchased from Dow Chemical Company, Midland, MI. Divinylbenzene (DVB) containing 20\% (3- and 4ethyl styrene) and 80\% (3- and 4- divinylbenzene) was purchased from Monomer - Polymer and Dajac Laboratories, Inc, Feasterville, PA. The ratio of 3- and 4- DVB was 60:40 as determined by GC. 1,3-diisopropenylbenzene was obtained from Fluka Chem. Co. Milwaukee, WI. VBC, DVB, and 1,3-diisopropenylbenzene were used directly without purification. Nbutyllithium (n-BuLi), purchased from Chemetall Foote Co. was diluted with pre-dried hexane. The concentration of $\mathrm{n}-\mathrm{BuLi}$ was determined by a standard double titration procedure [48]. All polymerizations were conducted in an one gallon stirred batch reactor at the desired temperature according to the procedures described previously [49]. Polymerization kinetics measurement (e.g., plots of monomer conversion vs. polymerization time) were obtained as described previously [47]. The polymers were characterized by various analyses including Tg by DSC, molecular weight by GPC, and microstructure by proton NMR.

\section{Functionalized 1,3-butadiene monomers:}

The synthetic procedure for making functionalized 1,3-butadienes involves two steps: (1) Preparation of 2-bromo-3-(N,N-dialkyl or cyclic alkyl amino)propene and then (2) Reaction with vinyl magnesium bromide to form 2-(N,N-dialkyl or cyclic alkyl amino)methyl 1,3- butadiene.

\section{Synthesis of 2-(N-hexamethyleneimino)-methyl 1,3-butadiene (HMI-Isoprene)}

A solution of 2,3-dibromopropane ( 0.1 mole) in diethyl ether was slowly added to a solution of hexamethyleneimine (0.4 mole) in ethyl ether at 0 $0 \mathrm{C}$. The reaction mixture was stirred overnight at room

temperature. To quench, $1 \mathrm{M} \mathrm{NaOH}$ solution was added to the mixture; the organic layer was collected using a separatory funnel, extracted with diethyl ether, and washed with water two times. After drying with sodium sulfate, the filtrate was evaporated and the resulting residue was distilled in vacuum to yield 2- bromo-3-(N-hexamethyleneimino)propene. The boiling point and yield were $65-680 \mathrm{C}$ at $30 \mathrm{~mm}-\mathrm{Hg}$ and and $60 \%$, respectively. The molecular structure of 2-bromo-3-(N-hexamethylene-imino)propene was verified by proton NMR. Vinyl magnesium bromide in tetrahydro- 
furan (THF, $0.085 \mathrm{~mol}$ ) was added dropwise to a flask containing 2-bromo-3-(N-hexamethylene-imino)propene (0.056 mol) in the presence of [1,3bis(diphenylphosphino) propane] dichloronickel(II) $(0.21 \mathrm{~mole})$ at $00 \mathrm{C}$. After stirring for 24 hours at room temperature, the hydrolysis of the reaction mixture by saturated ammonium chloride solution was carried out and followed by extraction with diethyl ethyl three times. The organic material was dried by sodium sulfate and then filtered. After evaporating the solvent, the residue was distilled in vacuum to give a colorless liquid of 2(N-hexa-methyleneimino)-methyl 1,3-butadiene. The boiling point and yield were - $1140 \mathrm{C}$ at $30 \mathrm{~mm}-\mathrm{Hg}$ and $60 \%$, respectively. The molecular structure of the resulting product was verified by proton NMR.

\section{Synthesis of 2-(N,N-diethylamino)methyl-1,3-butadiene}

The procedure described above was utilized except that $\mathrm{N}, \mathrm{N}$-diethylamine was used in place of hexamethyleneimine. The yield for the intermediate product, 2-bromo-3-(N,N-diethylamino)propene, was 98\%. The boiling point and yield of the final product, 2-(N,N-diethylamino)-methyl-1,3butadine were 112-114 at $30 \mathrm{~mm}-\mathrm{Hg}$ and 50\%, respectively. Preparation of 2-(N-pyrrolidino)-methyl-1,3-butadiene, 2- (N-piperidino)-methyl-1,3butadiene and 2-(N-morpholino)-methyl-1,3-butadiene were conducted similarly by using pyrrolidine, piperidine and morpholine, respectively.

\section{Functionalized ethyl styrene monomers}

A procedure for making 1-(2-diethylaminoethyl)-4-vinylbenzene, similar to that used by Tsuruta [13], was employed except that the amide-amine complex was not preformed. The catalyst, $\mathrm{n}$-BuLi was directly added to a flask containing the amine and divinylbenzene (DVB). A commercially available $80 \%$ DVB containing $20 \%$ of ethylstyrene was used. The ratio of meta- to para-DVB was generally around 60:40.

\section{Synthesis of 3- and 4-(2- Pyrrolidinoethyl) Styrene (PES)}

Into a five-liter flask, equipped with a stirrer and a thermometer, was charged two liters of dry hexane. The hexane was cooled with a wet ice/acetone bath to 0 to $-50 \mathrm{C}$. To this was added, under nitrogen, 5 moles of neat pyrrolidine, followed by 6.25 moles of $80 \%$ divinylbenzene (containing a $20 \%$ (mixture of 3- and 4-ethylstyrene; the ratio of 3-DVB to 4-DVB was around 60:40 as determined by GC). This homogenous solution was maintained at around -5 OC. To this cold mixture, 0.112 mole of n-butyl lithium ( $70 \mathrm{ml}$ of $15 \% \mathrm{n}$-BuLi solution in hexane) was added all at once. The reaction mixture turned green upon the initial addition of $\mathrm{n}-\mathrm{BuLi}$ and the temperature rose to $\sim 500 \mathrm{C}$. The reaction mixture turned brownish red and to the reaction mixture was allowed to cool down to $+50 \mathrm{C}$ with continuous stirring for one hour. The reaction was monitored by periodic sample analyses. The reaction was terminated by adding $5 \mathrm{ml}$. of isopropanol to the reaction mixture. GC analysis indicated that $70-80 \%$ of the DVB was consumed within 5-10 minutes after the addition of the n-BuLi with no further reaction taking place after that time. The isopropanol terminated reaction mixture was treated with $500 \mathrm{ml}$ of distilled water, and the organic layer was separated and dried with magnesium sulfate. The hexane filtrate was evaporated and the resulting residue distilled at reduced pressure to yield a 96:4 mixture of 3 and 4-(2-pyrrolidinoethyl) styrene (boiling point was $115-1200 \mathrm{C}$ at $1 \mathrm{~mm}-\mathrm{Hg}$ ) and 3 and 4-(2-pyrrolidino-ethyl)-1-ethylbenzene as determined by GC and proton NMR in CDCl3. The ratio of 3-(2-pyrrolidin-oethyl) styrene to 4-(2-pyrrolidinoethyl) styrene was normally 60:40. The unreacted DVB can be collected at 60-90 0C for recycling.

The preparation of the other amine functionalized styrene monomers, including HMI, piperidino, morpholino styrene were prepared similarly and their structures were confirmed by NMR.

\section{Functionalized methyl styrene monomers}

Pyrrolidinomethyl styrene (PMS), piperidinomethyl styrene (PIP-MS), hexamethyleneimino-methyl styrene (HMI-MS) and morpholinomethyl styrene (MOR-MS) were prepared from vinylbenzyl chloride (VBC) and the respective secondary amines using procedures similar to those published previously [43]. Since the starting VBC contains a mixture of 3- and 4- isomers, the resulting aminomethyl styrene monomers also contained varying amounts of 3-and 4- isomers. Due to the similar boiling points of the two isomers, no attempt was made to separate them although the structures of these aminomethyl styrenes were confirmed by NMR.

\section{Functionalized alpha-methyl styrene monomers}

Synthesis of 3-(2-pyrrolidino-1-methyl ethyl)-alpha-methyl styrene (PAMS)

3-(2-pyrrolidino-1-methyl ethyl)-alpha-methyl styrene (PAMS) was prepared using similar procedures described above for PES except that 3diisopropenylbenzene (DIPB) was used instead of DVB. PAMS was obtained by vacuum distillation with the unreacted DIPB collected at the earlier stages of distillation and re-used for making additional PAMS. The average PAMS yield was $60-70 \%$ with a boiling point of $120-1230 \mathrm{C}(1 \mathrm{~mm}-$ $\mathrm{Hg}$ ). The structure of PAMS was verified by NMR. Other amine functionalized alphamethyl styrene monomers including 3-(2-piperidino-1-methyl ethyl)-alpha-methyl styrene, 3-(2- hexamethyleneimino-1-methyl ethyl)-alpha-methyl styrene were prepared similarly.

\section{Preparation of in-chain amine functionalized styrene - 1,3-butadiene copolymers (SBR)}

In-chain amine functionalized SBRs were prepared using a standard anionic polymerization technique [15] by adding various amounts (0.25 to $20 \mathrm{wt} \%$ ) of amine functionalized isoprene or styrene monomers to the reactor containing a pre-dried styrene - 1,3 butadiene premix in hexane solution. The concentration of premix is normally around $20 \%$ by weight. The ratio of the combined styrene and functionalized monomer to 1,3 -butadiene was around 20:80 by weight. The polymerization was normally conducted at 70 to $750 \mathrm{C}$ in a mechanically stirred one gallon glass batch reactor 
equipped with an internal water cooling and steam heating coil. A temperature controller was used to maintain the polymerization temperature within $20 \mathrm{C}$ of the set temperature. The polymerization kinetics data [16] was obtained by periodic sampling during the reaction. The polymerization samples were coagulated with a n-decane/ethanol mixture and the solution analyzed by GC for the residual unreacted functional monomer, styrene, and 1,3- butadiene. This general procedure was used for preparing most of functionalized polymers discussed in this paper and is illustrated in the following example of preparing in-chain PES functionalized SBR. Preparation of in-chain pyrrolidine functionalized SBR In this experiment, a random 2/18/80 PES/styrene/1,3-butadiene terpolymer was prepared with the $2 \%$ pyrrolidine functionalized styrene (PES) randomly distributed along the polymer chain. In this procedure, $2068 \mathrm{~g}$ of a silica/alumina/molecular sieve dried premix containing 20.14 total weight percent of PES, styrene and 1,3-butadiene (2/18/80 weight ratio) in hexanes was charged into a one-gallon reactor and preheated to $700 \mathrm{C}$. The PES contained a mixture of 3- and 4-(2-pyrrolidinoethyl) styrene and a small amount (normally 4\% or less) of mixed 3- and 4-(2-pyrrolidinoethyl)-1-ethylbenzene. The ratio of 3-(2- pyrrolidinoethyl) styrene to 4-(2-pyrrolidinoethyl) styrene could be varied, although it was normally 60:40. Neat N, N, N', N'-tetramethylethylenediamine (TMEDA; $0.48 \mathrm{ml}$ ) and n-butyl lithium ( $\mathrm{n}-\mathrm{BuLi} ; 1.5 \mathrm{ml}$ of $1.6 \mathrm{M}$ ) in hexane were separately added to the reactor. The molar ratio of TMEDA to $\mathrm{n}-\mathrm{BuLi}$ was 1.5:1.The polymerization was carried out at $700 \mathrm{C}$ for 90 minutes. GC analyses of the residual monomers contained in the polymerization mixture indicated that the all monomers were consumed at this time; the polymer cement was shortstopped with ethanol, and then removed from the reactor and stabilized with $1 \mathrm{phr}$ (parts per 100 parts of rubber) of BHT (t-butylated hydroxytoluene). After evaporating the hexane, the resulting polymer was dried in a vacuum oven at $500 \mathrm{C}$. The GC analyses of the residual monomers with respect to the polymerization time also indicated that the PES was randomly distributed along the polymer chain. The PES-styrene-butadiene terpolymer produced was determined to have a glass transition temperature (Tg) of - $340 \mathrm{C}$. It was also determined to have a microstructure which contained 48.0 percent 1,2-polybutadiene units, 32.9 percent cis/trans 1,4-polybutadiene units, 17.4 percent random polystyrene units, and 1.7 percent of PES units. The Mooney viscosity (ML-4) at $100 \mathrm{OC}$ for this polymer was determined to be 42 . The GPC data of this polymer was also determined to have a Mn of $181,900 \mathrm{~g} / \mathrm{mole}$ with a polydispersity $(\mathrm{Mw} / \mathrm{Mn})$ of 1.05 , agreed well with the calculated $\mathrm{Mn}$ of $174,000 \mathrm{~g} / \mathrm{mole}$. Other PESstyrene- butadiene terpolymers containing $0.25,0.5,1.0$, and 5.0 weight $\%$ PES having similar Tg's ( -32 to $-370 \mathrm{C})$ were prepared similarly for compound evaluation.

\section{Preparation of hexamethyleneimine (HMI) functionalized SBR}

In this experiment, a 1/24/75 HMI-I/styrene/1,3-butadiene terpolymer was prepared with the $1 \% \mathrm{HMI}$ functionalized isoprene. $2350 \mathrm{~g}$ of a silica/alumina/molecular sieve dried premix containing 19.50 weight percent styrene and 1,3-butadiene in hexane was charged into a one-gallon (3.8 liter) reactor and preheated

at 70 0C. Neat 2-(N-hexamethyleneimino)-methyl 1,3-butadiene (HMI-I; $4.6 \mathrm{~g}$ ) was added to the premix in the reactor. N, N, N', N'-tetramethyethylenediamine (TMEDA; $2.9 \mathrm{ml}$ of $1 \mathrm{M}$ solution in hexane) and nbutyl lithium ( $\mathrm{n}-\mathrm{BuLi} ; 2.3 \mathrm{ml}$ of $1.6 \mathrm{M}$ ) in hexane were separately added to the reactor. The polymerization was carried out at $700 \mathrm{C}$ for 90 minutes. Similar procedures described in previous example were used here for polymerization, kinetics and polymer work-up. The (HMI-I)-styrene-butadiene terpolymer produced was determined to have a glass transition temperature $(\mathrm{Tg})$ of - 33 0C. It was also determined to have a microstructure which contained 41 percent 1,2-polybutadiene units, 34 percent 1,4-polybutadiene units and 25 percent random polystyrene units. It also contained about 1 weight of HMI units. The Mooney viscosity (ML-4) at $1000 \mathrm{C}$ for this SBR was determined to be 27 . The GPC data of this polymer was also determined to have a Mn of 129,000 g/mole with a polydispersity (Mw/Mn) of 1.05 , agreed extremely well with the calculated Mn of 126,000 g/mole. Other 25/75 SBRs containing 0, 0.25, and 0.5\% HMI-Isoprene were prepared similarly for compound evaluation.

\section{Tin coupled HMI functionalized 25/75 SBR}

A tin coupled 0.5/24.5/75 HMI-I/styrene/1,3-butadiene terpolymer was prepared with 0.5 weight percent of 2-(N-hexamethyleneimino)-methyl 1,3-butadiene. $2350 \mathrm{~g}$ of a silica/alumina/molecular sieve dried premix containing 19.50 weight percent styrene and 1,3-butadiene in hexane was charged into a onegallon (3.8 liter) reactor and preheated at $700 \mathrm{C}$. Neat 2-(N-hexamethyleneimino)-methyl 1,3-butadiene (HMI-I; $2.3 \mathrm{~g}$ ) was added to the premix in the reactor. . N, N, N', N'-tetramethyethylenediamine (TMEDA; $2.9 \mathrm{ml}$ of 1M solution in hexane) and n-butyl lithium (n-BuLi; 2.3 $\mathrm{ml}$ of $1.6 \mathrm{M}$ ) in hexane were separately added to the reactor. The polymerization was carried out at $700 \mathrm{C}$ for 90 . The polymerization was carried out at $700 \mathrm{C}$ for 90 minutes. The GC analysis of the residual monomer contained in the polymerization mixture indicated that the all monomers were consumed at this time. $0.9 \mathrm{ml}$ of a $1 \mathrm{M}$ solution of tin tetrachloride in hexane was then added to the polymerization mixture. The coupling reaction was allowed to proceed at $700 \mathrm{C}$ for 30 minutes. The Mooney viscosity (ML-4) at $1000 \mathrm{C}$ for this tin coupled HMI-SBR was 83 . The coupling efficiency was $69 \%$ based on GPC measurement.

\section{Polymer and monomer Characterization}

\section{Gel permeation chromatography (GPC)}

Size-exclusion chromatography (SEC) was performed using a Wyatt Technologies mini Dawn light scattering detector coupled with a Hewlett Packard 1047A refractive index detector. Two Polymer Laboratories C microgel columns in series were utilized with tetrahydrofuran as the carrier solvent at a flow rate of $0.7 \mathrm{ml} / \mathrm{min}$ and a column temperature of 40C. Sample preparation involved filtering a $0.12 \mathrm{wt} \%$ solution of polymer in THF through a $1.0 \mathrm{E}$ m filter prior to injection. Polystyrene standards were used to calibrate the instrument.

\section{Nuclear magnetic resonance (NMR)}

Polymer microstructures were determined by proton and /or C-13 solution NMR on a Varian $400 \mathrm{MHz}$ Fourier transform spectrometer. Spectra were obtained using $50 \%$ (by volume) solutions in $\mathrm{CDCl} 3$ for the functionalized monomers and 5 weight \% of polymer in $\mathrm{CDCl} 3$ for the functionalized polymers. Tetramethylsilane was used as a reference. 


\section{Differential scanning calorimetry (DSC)}

Differential scanning calorimetry was conducted on a TA 2910 instrument. All samples were cooled to $-120 \mathrm{C}$ and then heated at $100 \mathrm{C} / \mathrm{min}$ to determine the glass transition temperature ( $\mathrm{Tg}$ ). The on-set $\mathrm{Tg}$ is used for all polymers reported in this paper.

\section{Gas Chromatogrphy (GC)}

Monomer (including functionalized monomers) concentration was determined by gas chromatography on a Hewlett Packard 5890 Series II Gas Chromatogram with a $60 \mathrm{~m} \times 0.250 \mathrm{~mm}$ DB-5 column at 0.25 micron.

\section{Results and Discussion}

\section{Monomer Synthesis}

\section{Functionalized 1,3-butadiene monomers}

Functionalized 1,3-butadiene monomers containing stable tertiary amino groups under the conditions of living anionic polymerization conditions were reported earlier by Stadlar [44] and later was expanded by Shears [45-46]. In their preparations, the 2-methyl group of isoprene was brominated directly or by the aid of sulfur dioxide. The aminomethyl functionalized 1,3-butadiene monomers were then formed by reacting the resulting brominated isoprene with secondary amines. Other 1,3-butadiene monomers containing polar functional functional groups such as cyano, hydroxy, carboxyl, and ester were prepared via the same procedure. Polymerization of these functionalized monomers with or without the presence of diene monomers, was studied using emulsion polymerization techniques [50].

As depicted in Eq. 1, our approach is significantly different. Starting from a commercially available 2,3-dihalopropene, its allylic halogen was reacted with a secondary amine to form a 3 -aminopropene. The aminomethyl functionalized butadiene monomers were then formed by adding a vinyl group to the resulting 3-aminopropene via a Grignard reagent, vinyl magnesium bromide. Although several functionalized 1,3-butadiene monomers were prepared by this method [51], only the one containing the hexamethyleneimine functionality (HMI-Isoprene) was used in the compound study due to the complexity of the preparation and the modest overall yield. Even though the structures of all the amine functional isoprene monomers prepared were confirmed by NMR, only the spectra of HMI-Isoprene are shown here (Figures 1a and 1b) for illustration purpose.

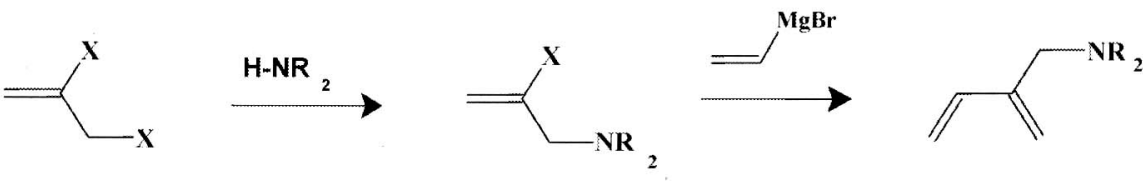

$\mathrm{X}=\mathrm{Br}$ or $\mathrm{Cl}$

$\mathrm{NR}_{2}=$ di-methyl amine, HMI, piperidine and pyrrolidine

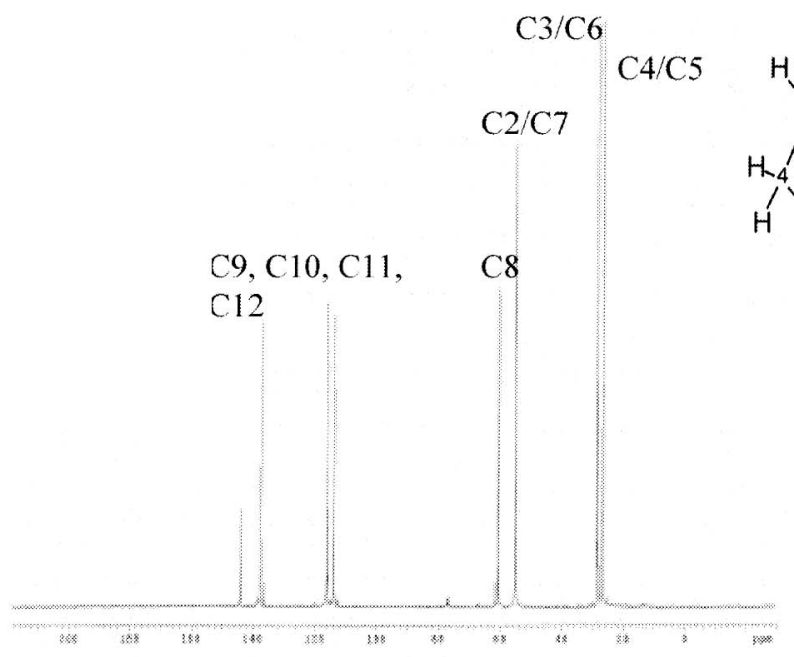

(1a)<smiles></smiles>

$\mathrm{H} 4 / \mathrm{H} 5$

$\mathrm{H} 10, \mathrm{H} 11(\mathrm{t}), \mathrm{H} 12(\mathrm{t} / \mathrm{c})$,

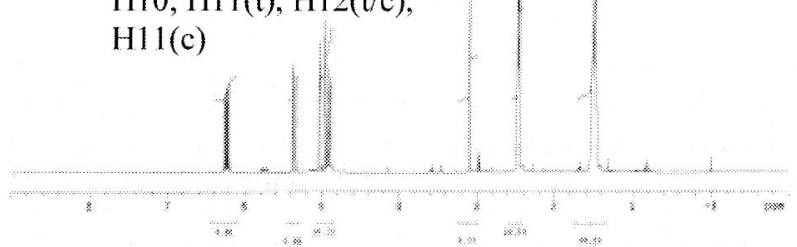

(1b)

Figures $1 \mathrm{a}$ and $1 \mathrm{~b} \cdot{ }^{13} \mathrm{C}$ and ${ }^{1} \mathrm{H}$ NMR spectra of 2-(hexamethyleneimino)methyl-1,3butadiene (HMI-Isoprene). Spectra were taken in 50:50 (vol.) mixtures in $\mathrm{CDCl}_{3}$

\section{Functionalized styrenic monomers}

Pyrrolidinomethyl styrene (PMS), piperidinomethyl styrene (PIP-MS), hexamethyleneiminomethyl styrene (HMI-MS), and morpholinomethyl styrene (MOR-MS) were prepared from vinylbenzyl chloride (VBC) and their respective secondary amines using similar procedures published previously [43, 52] (Eq.2). 


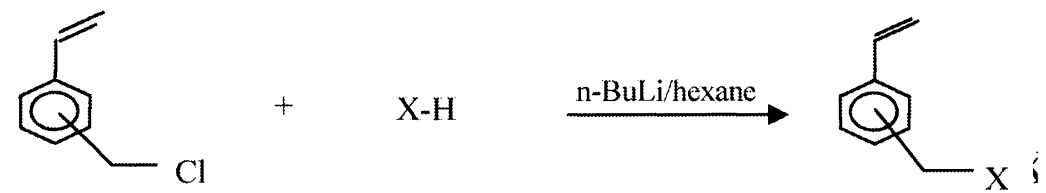

Because the starting VBC contains mixtures of varying amounts of 3- and 4- isomers, the resulting aminomethyl styrene monomers also contained varying amounts of the 3- and 4- isomers. Due to similarity of the boiling points of the two isomers, no attempt was made to separate the isomers. All these aminomethyl styrenic monomers were used directly for polymer preparation and subsequent compounding studies. The structures of these aminomethyl functionalized styrene monomers were confirmed via NMR analyses.

Since secondary amines are not basic enough to directly add to the vinyl double bond of divinylbenzene (DVB), the amine was pre-reacted with alkyl lithium to form an amine-amide complex as described in an earlier preparation of 4-(2-(N,N-diethylamino)ethyl) styrene and 4-(2-(N,Ndimethylamino)ethyl) styrene by Tsuruta [53-55]. Since the cyclic amino functionality was reported to be more effective than the aliphatic amino functional groups for reducing the hysteresis of a carbon black filled rubber compound [8], it is of interest to investigate the effectiveness of styrenic monomers containing cyclic amines. To that aim,

we have utilized similar procedures and prepared a series of styrenic monomers from DVB containing pyrrolidinoethyl, piperidinoethyl, hexamethyleneiminoethyl, and morpholinoethyl functional groups. To simplify the process, $\mathrm{n}$-BuLi was added directly to the mixture containing both DVB and secondary amine to avoid the additional step of preforming an amine-amide complex. It was found that about the same yields of products were obtained with or without preforming the cyclic amide-amine complexes. The cyclic amide formation must be much faster than the homo-polymerization of DVB at low temperature.

Due to the extremely high cost of pure 4-divinyl benzene, the relatively inexpensive commercial grade of DVB, containing a mixture of 3- and 4isomers and ethylstyrene, was used as the starting material. Since all of the vinyl groups in these three components are subject to the lithium amide addition, a rather complicated mixture of products is expected. Using pyrrolidine as an example (Eq. 3), the final products are expected to include 3(2-pyrrolidinoethyl) ethylbenzene [1], 4-(2-pyrrolidinoethyl) ethylbenzene [2], 3- (2-pyrrolidinoethyl) styrene [3], 4-(2-pyrrolidinoethyl) styrene [4], 1,3-bis (2-pyrrolidinoethyl)benzene [5], 1,4-bis(2-pyrrolidinoethyl)benzene [6], unreacted 3- and 4-divinylbenzene, and unreacted 3- and 4- ethylstyrene.

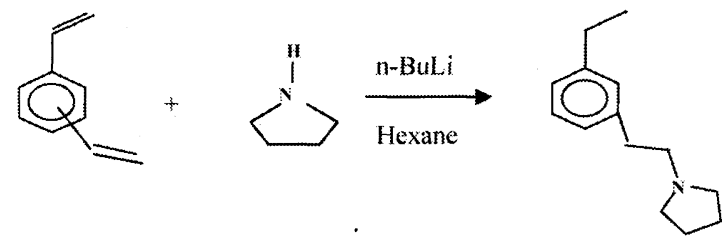

$80 \%(3-\& 4-D V B)$
[11

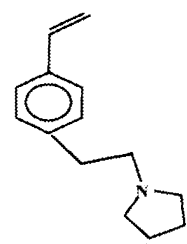

[4]

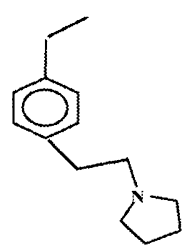

$[2 \mid$

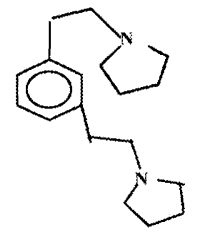

[5]

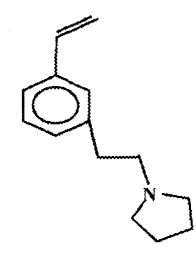

[3]

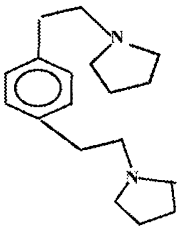

[6]

Of these six expected products, only the first four were observed by the GC analyses during the preparation and after the product purification by vacuum distillation. However, a small amount of a residual pale yellow solid was obtained at around $150-1600 \mathrm{C}$ at $1 \mathrm{~mm}-\mathrm{Hg}$. This solid was identified by NMR as a mixture of bis- adducts of compound 5 and 6 . Since the boiling points of these bis- adducts were so high, they could not be detected by GC under normal operating conditions. As shown in the GC chromatogram (Figure 2) of the distillate, the boiling points of compounds 1 to 4 are very close to each other, and separation of these four compounds would require significant effort and was not the focus of this study. Since the non-polymerizable by-products 1 and 2 are only minor products (normally less than 10\%) and they are compatible with the anionic catalyst system utilized in this study, no attempt was made to separate them from the major products 3 and 4 (93\% combined, see Table 1). In fact, the distillate containing all four compounds ( 1 to 4 ) was used directly for making the functionalized polymers which will be discussed later. 


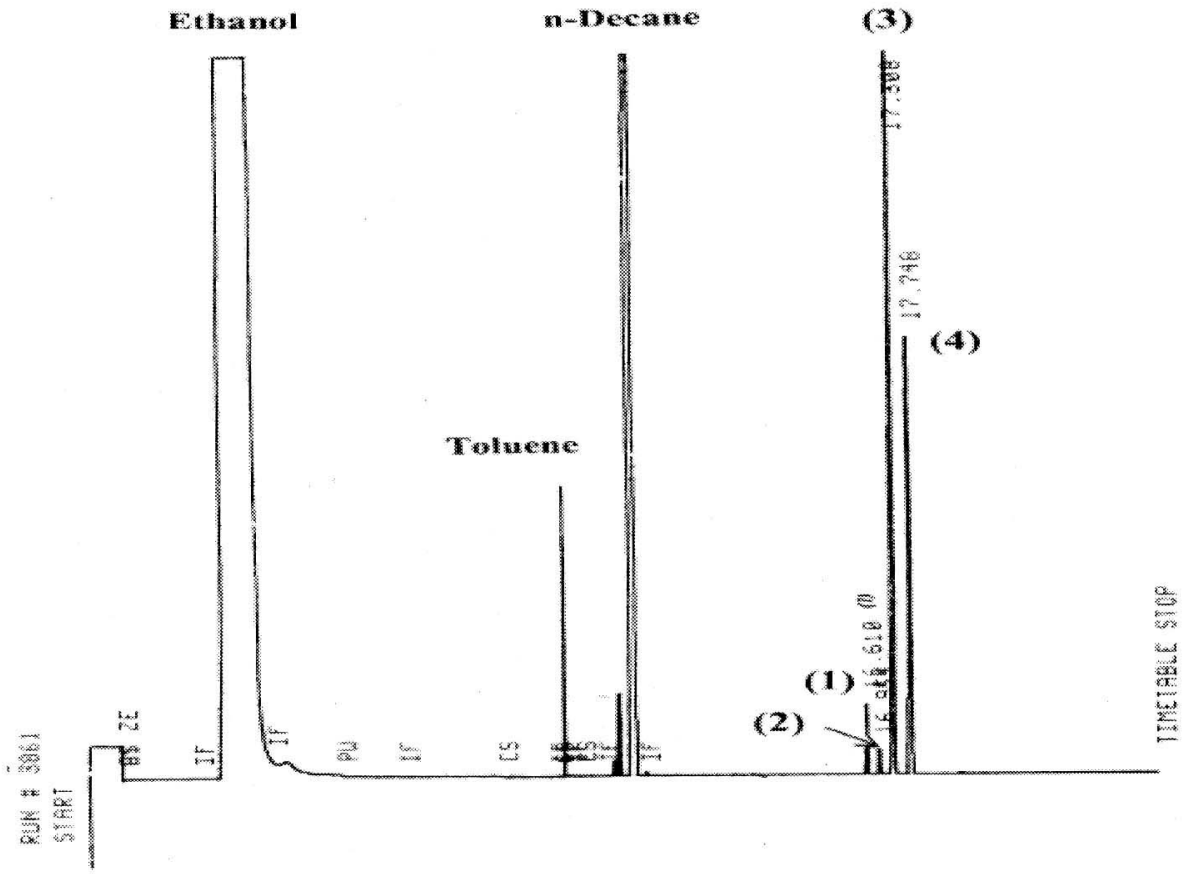

Figure 2. GC Chromatogram of a typical PES distillate. Compounds 1 to 4 are 3-(2-pyrrolidinoethyl) ethylbenzene (1), 4-(2-pyrrolidinoethyl) ethylbenzene (2), 3-(2-pyrrolidinoethyl) styrene (3) and 4- (2- pyrrolidinoethyl) styrene (4). Samples were dissolved in a mixture of $60 / 40$ denatured ethanol(contains $2 \%$ toluene) / n-decane.

Based on kinetic studies of p-substituted vinylbenzene derivatives with the diethyamide [53], Tsuruta found that the rate of an amide addition to vinyl double bond of para- substituted alkyl and aminoethyl vinylbenzyl compounds were 20-30 times slower than that of divinylbenzene. Our results are similar since the yields of pyrrolidinoethyl ethylbenzene (compounds 1 and 2, Table 1) and the bis- adducts (compounds 5 and 6 ) were low. Again, the structures of these aminoethyl functionalized styrene monomers were verified by NMR and the proton and carbon spectra of PES is shown in Figures $3 a$ and $3 b$, whereas the spectra of the bis adducts are shown in Figures $4 a$ and $4 b$.

Table 1. GC analysis of a typical PES distillate

\begin{tabular}{|c|c|c|c|}
\hline Compound & Name & RT (min) & Area \% \\
\hline \hline 1 & 3-(2-pyrrolidinoethyl) ethylbenzene & 16.61 & 5.08 \\
\hline 2 & 4-(2-pyrrolidinoethyl) ethylbenzene & 16.95 & 1.98 \\
\hline 3 & 3-(2-pyrrolidinoethyl) styrene & 17.31 & 58.38 \\
\hline 4 & 4-(2-pyrrolidinoethyl) styrene & 17.74 & 34.54 \\
\hline
\end{tabular}

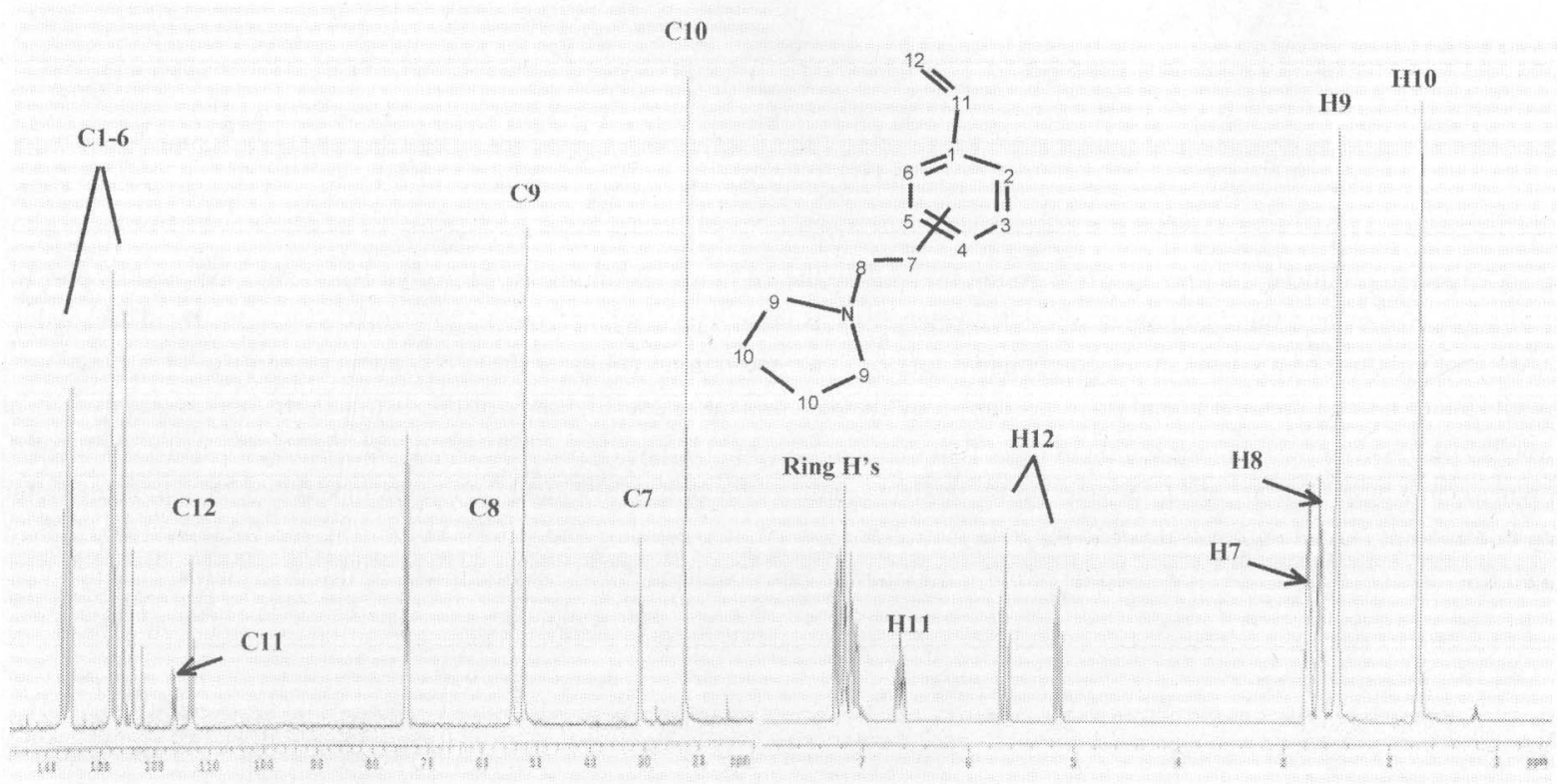

Figures $3 \mathrm{a}$ and $3 \mathrm{~b} .{ }^{1} \mathrm{H}$ and ${ }^{13} \mathrm{C}$ NMR spectra of 3- and 4-(2-pyrrolidinoethyl) styrene in 50:50 (vol.) mixtures in $\mathrm{CDCl}_{3}$. The PES sample contains 6-7\% mixtures of 3-and 4-(2-pyrrolidinoethyl) ethyl benzene 


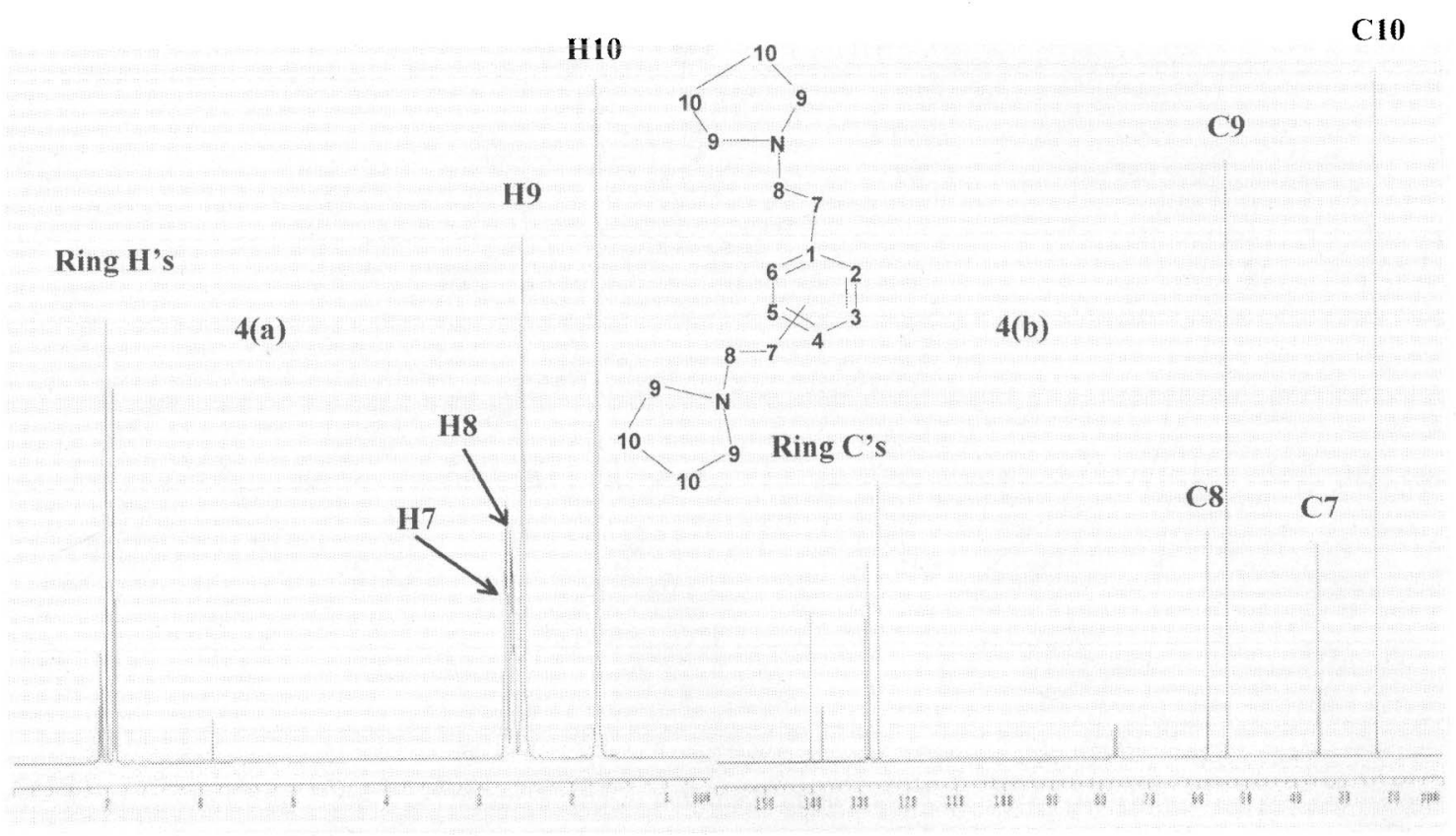

Figures $4 \mathrm{a}$ and $4 \mathrm{~b} .{ }^{1} \mathrm{H} \&{ }^{13} \mathrm{C}-\mathrm{NMR}$ spectra of 1,3- \& 1,4-bis(2-pyrrolidinoethyl)benzene

Other amine functionalized ethyl styrene monomers including piperidine and HMI were similarly prepared; however, only PES functionalied polymers will be discussed in this paper. Again, all these aminoethyl functionalized styrenic monomers were identified by NMR and only the spectra of PES and the bis- adducts (1,3- \& 1,4-bis(2-pyrrolidinoethyl)benzene) are shown here (Figures 3a, 3b, 4a,and 4b).

\section{Functionalized $\alpha$-methyl styrene monomers}

A similar procedure of making functionalized ethylstyrene was used except that a meta- diisopropenyl benzene (m-DIPB) was used as the starting material. As shown in Eq. 4, a pyrrolidine functionalized functionalized $\alpha$-methyl styrene was prepared by adding $\mathrm{n}$-BuLi directly to a hexane solution containing m-DIPB and pyrrolidine without preforming an amine-amide complex.
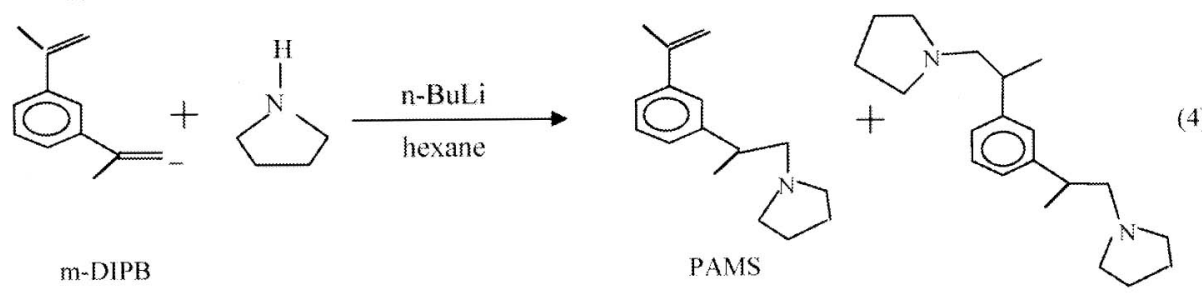

Since there is only meta- isomer in the starting material, m-DIPB, the expected final products will be mainly, the meta mono- adduct, 3-(2-pyrrolidino-1-methyl ethyl) $\alpha$-methyl styrene (PAMS). Also, similar to the PES system, the lithium pyrrolidine amide complex will also add to the isopropenyl double bond of PAMS to form a bis adduct, 1,3-bis (2-pyrrolidino-1-methyl ethyl) benzene. Again, the yield of the bis- adduct was very low (10\% or less) and could not be detected by GC under our normal operational conditions. Based on GC analysis, about $80 \%$ of m-DIPB was converted to the above products. The PAMS was collected by vacuum distillation at 130-135 0C at $1 \mathrm{~mm}-\mathrm{Hg}$. The bis- adduct was obtained at around $1650 \mathrm{C}$ at $1 \mathrm{~mm}-\mathrm{Hg}$. The structure of both mono and bis adducts were verified by NMR. The $1 \mathrm{H}$ and 13C NMR spectra for PAMS and the bisadduct are shown in Figures 5a, 5b, 6a, and 6b, respectively. 


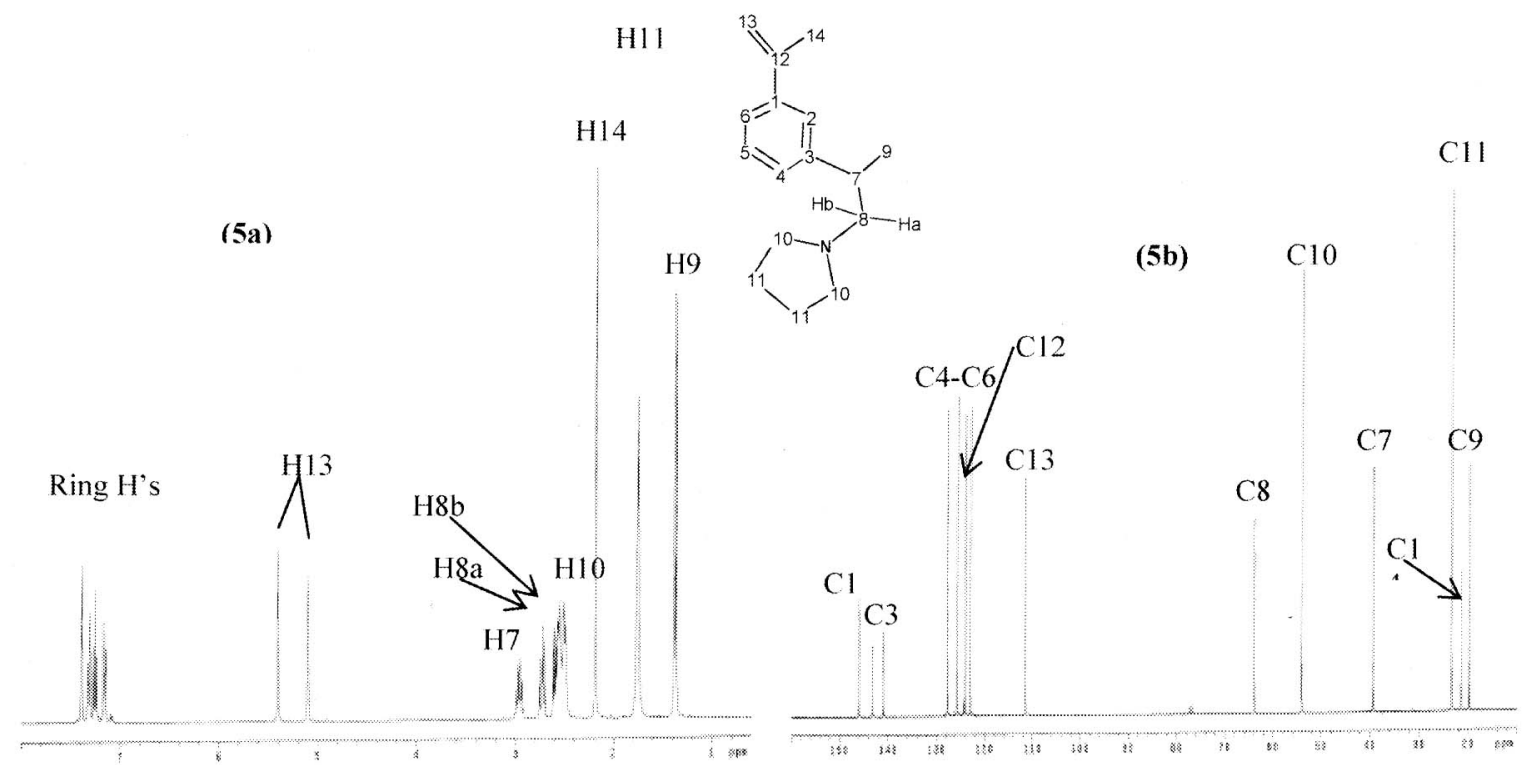

Figures 5a,b. ${ }^{1} \mathrm{H}$ and ${ }^{13} \mathrm{C}$ NMR spectra of PAMS (3-(2-pyrrolidino-1-methyl ethyl) $\alpha$-methyl styrene). Spectra were taken in 50:50 (vol.) mixtures in $\mathrm{CDCl}_{3}$.

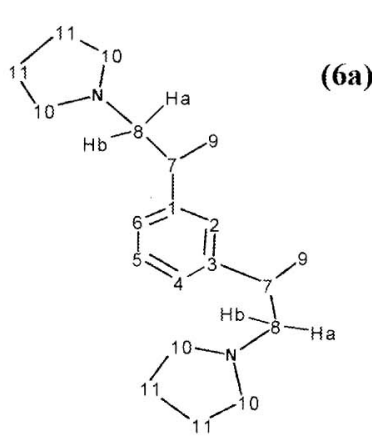

H9

(6a)

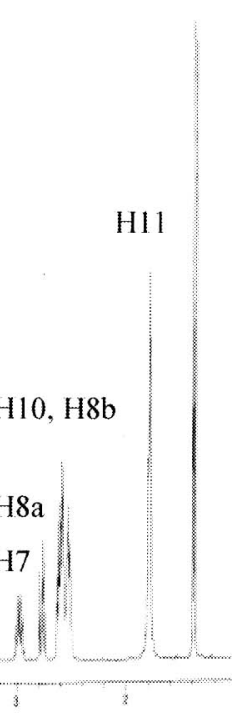

(6b)

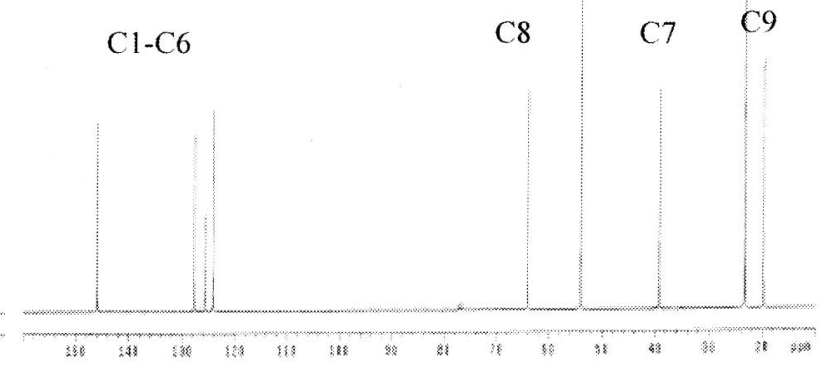

Figures 6a,b. ${ }^{1} \mathrm{H}$ and ${ }^{13} \mathrm{C}$ NMR spectra of 1,3-bis (2-pyrrolidino-1-methyl ethyl) benzene. Spectra were taken in 50:50 (vol.) mixtures in $\mathrm{CDCl}_{3}$

In comparison, PAMS is relatively simpler and more economical to prepare than the PES monomer due to simpler distillation procedures and the fact that unreacted m-DIPB can be readily recycled (due to its high purity). Other amine functionalized $\alpha$-methyl styrene monomers including piperidine and HMI were similarly prepared; however, only PAMS functionalized polymers are discussed in this paper.

\section{Polymerization}

\section{In-chain functionalization}

Living anionic polymerization of both amine functionalized isoprene [44, 56-57] and styrene monomers [58-60] have well established in the literature. However, most of these studies were conducted at extremely low temperatures. On the other hand, there is not much work known [43], regarding their copolymerization with conjugated dienes, the main monomers for making tires and other rubber products. In addition, the complexity and the cost of making most of these functional monomers may also prevent their development into feasible tire elastomers.

Since PES and PAMS can be readily prepared in good yield from relatively inexpensive DVB and DIPB, our immediate goal is to investigate whether these monomers can copolymerize with styrene, 1,3- butadiene and isoprene at temperatures around $70-750 \mathrm{C}$. Furthermore, if they exhibit similar polymerization kinetics as those of tire monomers, many other applications can be obtained utilizing the functional monomer approach. In addition to "in-chain" functionalization, functional initiator (head or $\alpha$-functionalization), chain-end (terminal or $\omega$ - end) functionalization, functional block copolymer formation, etc. It is reasonable to expect that there is no immediate use of homo- polymers of amine functional- 
ized styrenic monomer in tires, hence no attempt was made to homo- polymerize the functional monomers described above. However, some functional lithium initiators containing oligomeric functional monomers were in some cases prepared for comparative studies.

Because the presence and the amount of above functional monomers can be easily determined by GC, the kinetics of polymerization of dienes, styrene and the said functional monomers can be easily monitored by measuring the residual monomers (including functional monomers) remaining from samples periodically removed from the polymerization mixtures. It was found that by adding a small amount $(0.25$ to $20 \%)$ of functionalized styrene or $\alpha$-methyl styrene monomers to a premix containing 1,3-butadiene and styrene monomers in hexane, in-chain amine functionalized styrene-butadiene copolymers (SBR) or random terpolymers of functional styrene monomers, styrene and 1,3-butadiene can be easily prepared by nbutyl lithium modified with a polar modifier TMEDA at 70-75 0C. As shown in Figure 7, a plot of monomer conversions versus polymerization time, the polymerization of a monomer mixture consisting of 5/15/80 PES/styrene/1,3- butadiene was essentially complete after one hour when catalyzed by a 1.5/1 TMEDA (N,N,N'N'-tetramethylethylenediamine) modified n-BuLi at $700 \mathrm{C}$. This polymerization profile (Figure 7) also indicates that all three monomers polymerized at similar rates, although 1,3-Bd appeared to be slightly faster than styrene and PES. Nevertheless, it can be seen that PES is randomly distributed along polymer backbones. This is also apparent in the polymer composition plot shown in Figure 8 . The polymer composition of the resulting polymer was around 5/15/80 PES/styrene/1,3-Bd at any given time. The resulting terpolymer had a Tg of $-350 \mathrm{C}$ and a narrow molecular weight distribution $(\mathrm{Mw} / \mathrm{Mn})$ of 1.05 .A perfectly random terpolymer (i.e., all three monomers polymerize at exactly the same rate) can be obtained by increasing the amount of TMEDA from 1.5 to 2.5-3/1. However, the $\mathrm{Tg}$ of the resulting polymers were higher than our target of $-350 \mathrm{C}$.

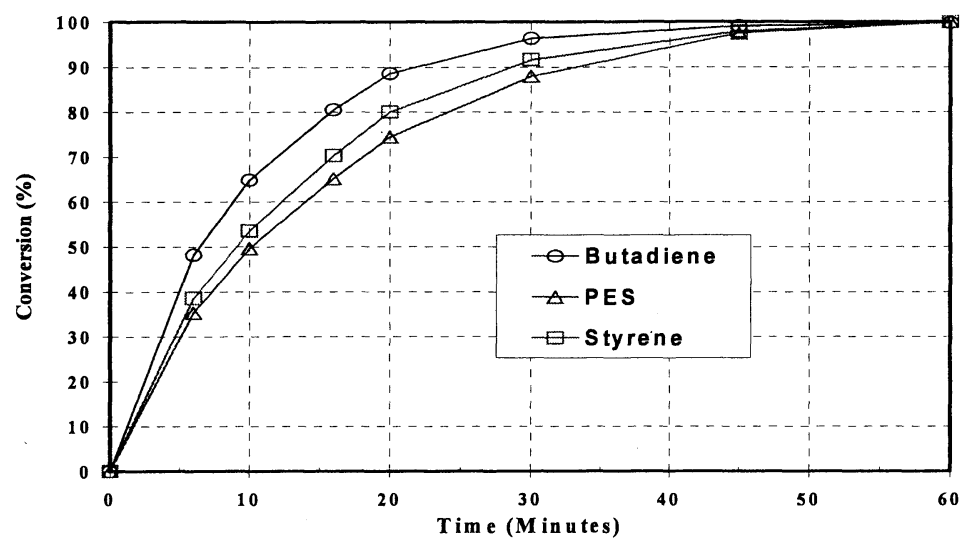

Figure 7. Terpolymerization of 5/15/80 PES/styrene/1,3-Bd via 1.5/1 TMEDA/n-BuLi at $70{ }^{\circ} \mathrm{C}$

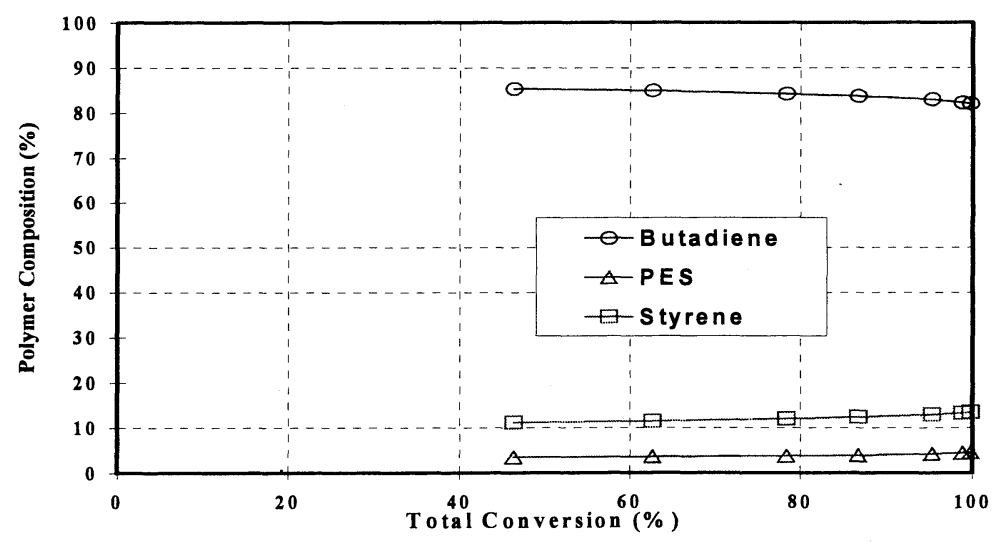

Figure 8. Polymer composition of 5/15/80 PES/styrene/1,3-Bd at varied total monomer conversions.

When PMS was used as the functional monomer, the polymerization results were very similar to those of the PES system under the same polymerization conditions. Bd polymerized faster than styrene or PMS, and again, PMS was only slightly slower than styrene. The characteristics of the resulting PMS/styrene/1,3-Bd terpolymer, or in-chain pyrrolidine functionalized SBR were very similar to those of PES in-chain functionalized SBR. However, it will be seen later that their effectiveness of reducing the hysteresis properties of rubber compounds are different. The rates of incorporation of other aminomethyl styrene monomers being HMI (HMI-MS), piperidine (PIP-MS) and morpholine (MOR-MS) in the copolymerization with styrene and 1,3-butadiene were very similar to that of PMS (3- and 4-(2-pyrrolidino methyl) styrene). Each version of amine functionalized SBR was compounded with carbon black to compare the effectiveness of each functional group to improve polymer filler interaction.

One of the concerns about PMS is its stability at high temperature or under prolonged heating, such as in the continuous polymerization. As shown in Scheme 1, it is very likely for pyrrolidine attached to PMS to be eliminated by n-BuLi or the living polymer ends to form lithium pyrrolidide and polymeric xylylene (X). Similar 1,6- elimination process has been reported previously [59, 61]. 


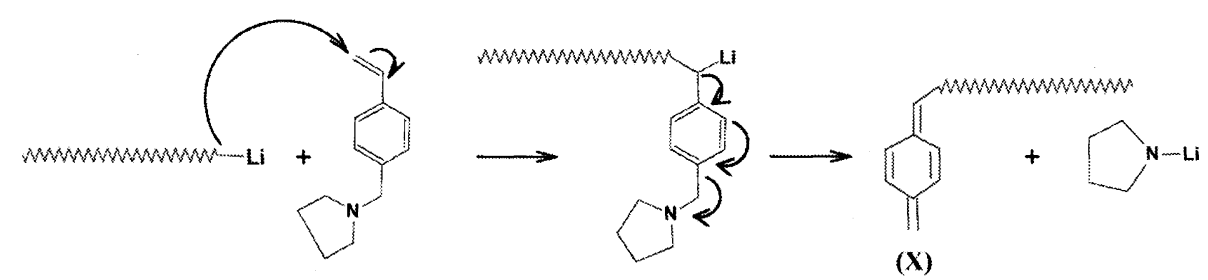

Scheme 1. Possible mechanism of pyrrolidine removal via 1,6-elimination process

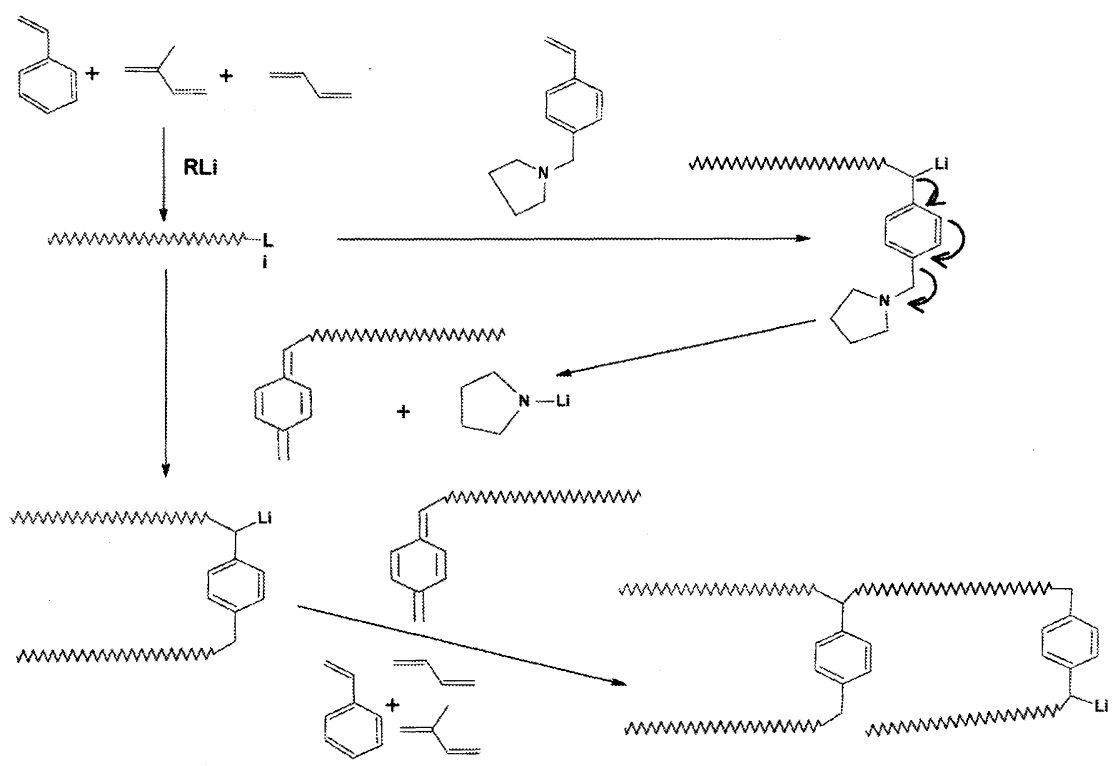

Scheme 2. Possible polymer branching mechanism for PMS functionalized

Furthermore, the very reactive xylylene (X) will readily react with RLi or the polymer live end, causing polymer branching (Scheme 2). Although this reaction did not appear to occur in a batch reaction at low PMS concentration and short polymerization times, it may proceed readily in a continuous process. This reaction is not expected to occur when PES or PAMS is used as the source of functional monomers. On the other hand, it was found that the amine functionalized $\alpha$-methyl styrene monomers did not polymerize well under the same polymerization conditions even though they did not interfere with polymerization of 1,3-Bd and styrene in the same polymerization mixtures. It is known that $\alpha$-methyl styrene does not usually homopolymerize or copolymerize with conjugated diene monomers at temperatures above $600 \mathrm{C}$ which is the ceiling temperature of $\alpha$ methyl styrene polymerization [62]. As a result, it has not been possible to co-polymerize $\alpha$-methyl styrene with diene monomers at temperatures above $600 \mathrm{C}$. At temperatures below $60 \mathrm{0C}$, polymerization has not proven to be commercially viable due to low polymerization rates and low conversion levels. To overcome this dilemma, a catalyst system containing dialkylmagnesium with alkali metal alkoxide was developed which enabled us to prepare copolymers or terpolymers of conjugated dienes/styrene with $\alpha$-methyl styrene at more typical commercial polymerization temperatures of 70 to $100 \mathrm{OC}$ [62]. Later, it was found that using a combination of alkali metal oxide (especially potassium or sodium alkoxide), TMEDA and $\mathrm{n}-\mathrm{BuLi}, \alpha$-methyl styrene can be copolymerized with conjugated dienes and styrene at high polymerization temperatures as well [63]. Although the ceiling temperature of PAMS was not determined, it was expected that these previously disclosed catalyst systems would also work for the amine functionalized $\alpha$-methyl styrene. It is known that polymer branching normally occurs [64] in the catalyst systems involving TMEDA and the combination of alkali metal alkoxide and $\mathrm{n}-\mathrm{BuLi}$ (superbases). Also, polymer branching is not desirable if the goal is to reduce compound hysteresis. For these reasons, the amount of alkali metal alkoxide was kept low ( 0.015 to 0.02 molar ratio to n-BuLi) in our initial attempts of copolymerizing PAMS with styrene and 1,3-Bd. As shown in Figure 9, the polymerization of 5/15/80 PAMS/styrene/1,3-butadiene was essentially complete in one hour at $700 \mathrm{C}$ using a catalyst system consisting of $0.02 / 1.5 / 1 \mathrm{KOR} / \mathrm{TMEDA} / \mathrm{n}-\mathrm{BuLi}$. 


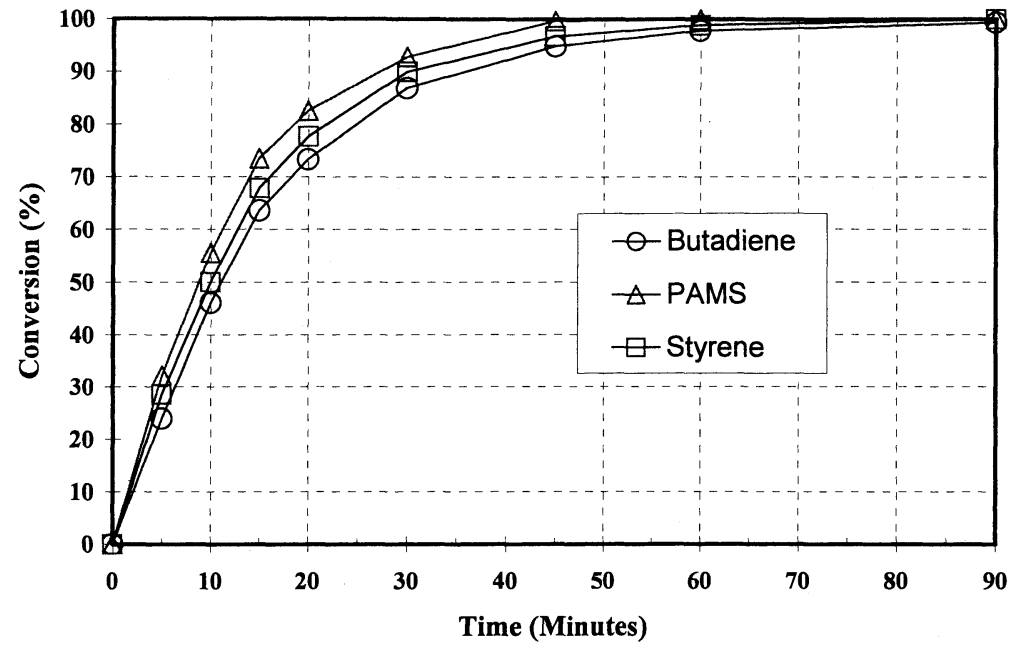

Figure 9. Terpolymerization of 5/15/80 PAMS/styrene/1,3-butadiene via 0.02/1.5/1 KDMO/TMEDA/n-BuLi at $70{ }^{\circ} \mathrm{C}$.

The polymerization profile also indicates that PAMS not only polymerized but also randomly copolymerized with styrene/1,3-Bd at such a low quantity of potassium alkoxide, namely 0.02 molar ratio to n-BuLi. Potassium 3,7-dimethyl-3-octanoxide (KDMO) was used for this polymerization. However, we found that other alkoxide such as potassium t-amylate, phenoxide (e.g., potassium p-dodecylphenolate) and sulfonate (e.g., potassium dodecylbenzesulfonate) worked as well. Similar to our previous finding [16] of enhanced styrene polymerization rate with the use of alkali metal alkoxide, both PAMS and styrene

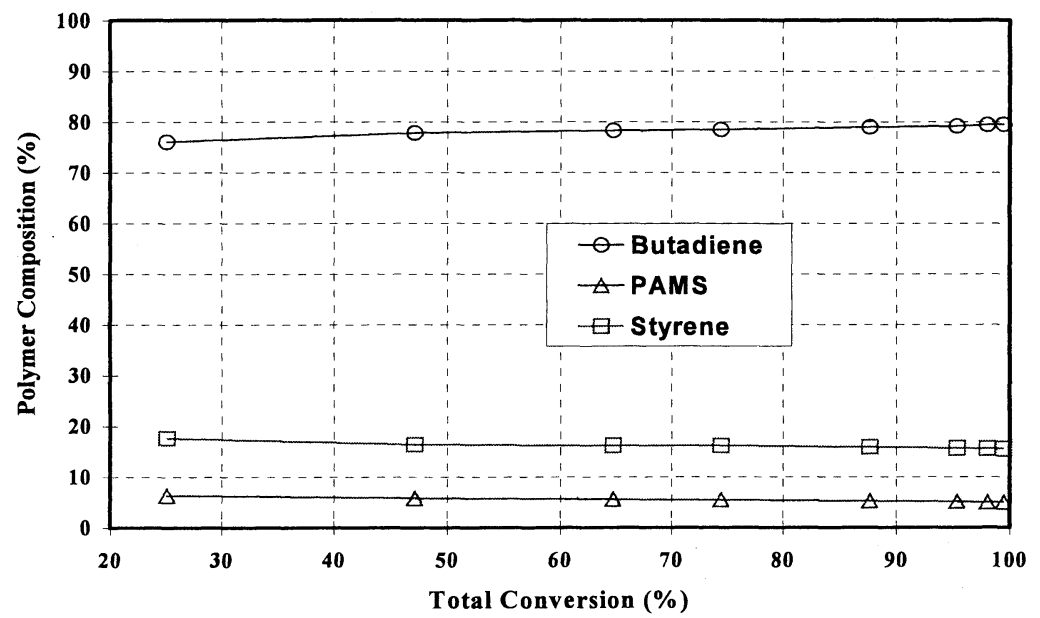

Figure 10. Polymer composition of a 5/15/80 PAMS/styren/1,3-butadiene terpolymer via $0.02 / 1.5 / 1 \mathrm{KDMO} / \mathrm{TMEDA} / \mathrm{n}$-BuLi at $70{ }^{\circ} \mathrm{C}$

polymerized slightly faster than 1,3-Bd (Figure 9). Again, the random nature of the resulting terpolymer can be seen from Figure 10 as relatively constant polymer composition of 5/15/80 PAMS/styrene/1.3-Bd was obtained at any polymerization time. Since the level of KOR used was so low, the molecular weight distribution of the terpolymer was very narrow $(\mathrm{Mw} / \mathrm{Mn}=1.05)$, similar to those terpolymers prepared from PES and PMS.

It is interesting to note that similar to non-chelating ethers (e.g., diethylether, THF) and tertiary amines (e.g., triethylamine), the functional styrene monomers discussed here behaved as weak modifiers for alkyl lithium to control the vinyl content and randomize the styrene distribution of polymers formed. In fact, as shown in Table 2, low vinyl SBR containing various amount of pyrrolidine functionality can be prepared by copolymerizing PES with 1,3-butadiene using n-BuLi alone, with no TMEDA modifier [19].

Table 2. Pyrrolindine functionalized SBR via copolymerizing PES with 1,3- butadiene via n-BuLi alone at $70{ }^{\circ} \mathrm{C}$.

\begin{tabular}{|c|c|c|}
\hline$\%$ PES & $\operatorname{Tg}\left({ }^{0} \mathrm{C}\right.$, on-set $)$ & $\%$ Vinyl $\left({ }^{1} \mathrm{HNMR}\right)$ \\
\hline 0 & -97 & 8 \\
\hline 1 & -94 & 9 \\
\hline 2 & -92 & 11 \\
\hline 5 & -83 & 18 \\
\hline
\end{tabular}

The amine functionalized low vinyl SBR can also be prepared using PAMS as the functional monomer; however, potassium alkoxide (or phenolate, sulfonate) has to be used with n-BuLi. Otherwise, the PAMS monomer would not polymerize. Plots of copolymerization of 5/95 PAMS/1,3-Bd and polymer composition of a copolymer containing 5\% PAMS are shown in Figures 11 and 12 . The glass transition temperature and vinyl content 
(-82 0C and 17\% vinyl, respectively), of this polymer were nearly the same as the copolymer prepared using PES as shown in Table 2.

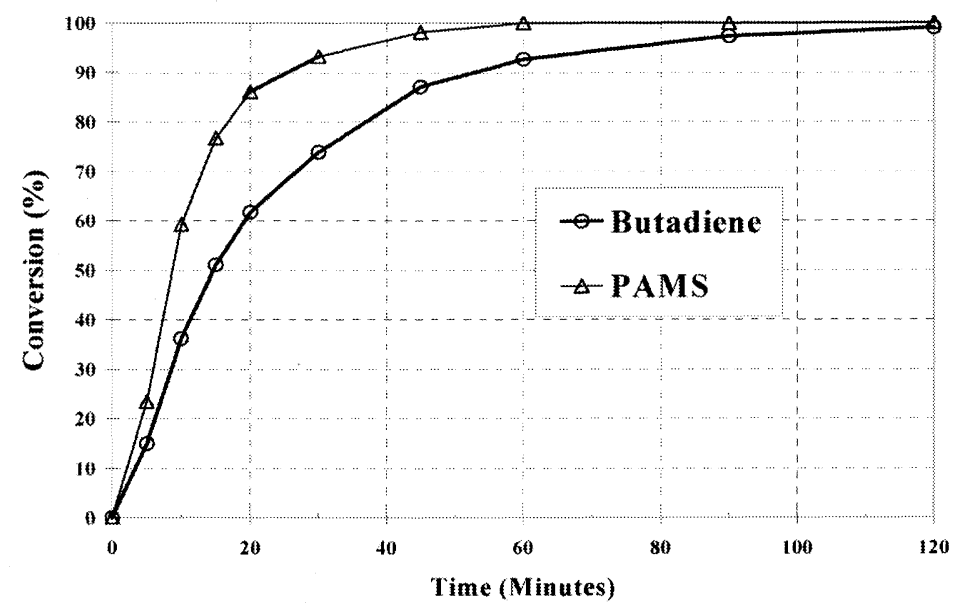

Figure 11. Random copolymerization of 5/95 PAMS/1,3-butadiene via 0.02/1 KOAm/n-BuLi at $70{ }^{\circ} \mathrm{C}$

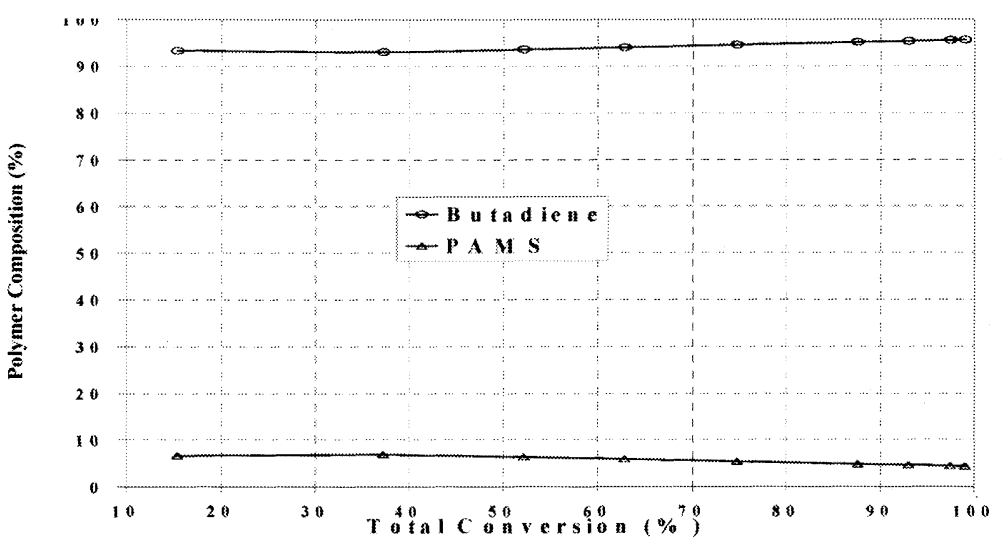

Figure. 12 Polymer composition of 5/95 PAMS/1,3-butadiene copolymer via $0.02 / 1 \mathrm{KOAm} / \mathrm{n}-\mathrm{BuLi}$ at $70{ }^{\circ} \mathrm{C}$.

Considering all of the physical properties of polymers which is used in tire compounds, the glass transition temperature (Tg) is perhaps the most important factor influencing the traction, rolling resistance and treadwear [65]. Due to minor catalyst modification effects of these functional monomers, the level of TMEDA used for making polymers has to be adjusted in order to yield polymers having similar Tg's for fair compounding comparisons. The target $\mathrm{Tg}$ of polymers synthesized for this study was $-350 \mathrm{C}$. As illustrated in Table 3, a series of pyrrolidine functionalized SBRs having a $\mathrm{Tg}$ near $-350 \mathrm{C}$ can be prepared using varied amounts $(0.25$ to $5 \%)$ of PES by adjusting the TMEDA level.

Table 3. Pyrrolidine functionalized SBRs containing 0.25 - 5\% PES having Tg near $-350 \mathrm{C}$ for compounding studies. Polymerization was conducted at $70{ }^{\circ} \mathrm{C}$ with varied amount of TMEDA.

\begin{tabular}{|c|c|c|c|c|}
\hline$\%$ PES & Initial monomer charge (wt \%) & TMEDA/n-BuLi & $\operatorname{Tg}\left({ }^{0} \mathrm{C}\right.$, on-set) & ML-4 \\
\hline 0 & PES/styrene/1,3-Bd & & & \\
\hline 0.25 & $0 / 20 / 80$ & $2 / 1$ & -35 & 45 \\
\hline 0.5 & $0.25 / 19.75 / 80$ & $2 / 1$ & -33 & 48 \\
\hline 1 & $0.5 / 19.5 / 80$ & $1.9 / 1$ & -34 & 50 \\
\hline 2 & $1.0 / 19 / 19$ & $1.8 / 1$ & -35 & 51 \\
\hline 5 & $2.0 / 18 / 80$ & $1.65 / 1$ & -36 & 49 \\
\hline
\end{tabular}

Unlike amine functionalized styrene monomers, the hexamethyleneimino isoprene (HMI-I) reacted at a much higher rate under similar polymerization conditions. In fact, according to GC analysis, the HMIisoprene was completely consumed a few minutes after the addition of the n-BuLi initiator. The presence of HMI functionality in the resulting polymer was confirmed by NMR. Obviously, a short block of HMI-I or a HMI-I rich SBR block was positioned at the beginning of the polymer chain when HMI-I was initially charged to the premix containing styrene and 1,3-butadiene. A series of HMI functionalized 25/75 SBRs containing various amount of HMI-I ( 0 to $1 \%$ by weight) were prepared similarly for compound evaluation (Table 4). As illustrated in Table 4, the molecular weight distributions are quite narrow for these HMI functionalized SBRs much like other nBuLi catalyzed living polymers, they can also be coupled with tin or silicon tetrachloride for added benefits such as improved polymer-filler interaction and processability [22]. 
Table 4. HMI functionalized 25/75 SBR via copolymerization with 0 to $1 \%$ HMI-Isoprene monomer at $70{ }^{\circ} \mathrm{C}$.

\begin{tabular}{|c|c|c|c|c|c|c|c|}
\hline & & & & & GPC & & \\
\hline$\% \mathrm{HMI}$ & Coupler & $\operatorname{Tg}\left({ }^{\circ} \mathrm{C}\right.$, on-set $)$ & $M L-4$ & $\operatorname{Mn}\left(x 10^{-3}\right)$ & $\operatorname{Mw}\left(\times 10^{-3}\right)$ & $M w / M n$ & $\%$ of peak \\
\hline 0 & None & -33 & 23 & 137 & 139 & 1.015 & \\
\hline 0.25 & None & -36 & 21 & 126 & 128 & 1.016 & \\
\hline 0.5 & None & -32 & 27 & 139 & 142 & 1.022 & \\
\hline 1 & None & -33 & 27 & 129 & 136 & 1.054 & \\
\hline \multirow{3}{*}{0.5} & & & & 677 & 812 & 1.199 & 42 \\
\hline & $\mathrm{SnCl}_{4}$ & -32 & 83 & 329 & 335 & 1.018 & 27 \\
\hline & & & & 145 & 155 & 1.069 & 31 \\
\hline
\end{tabular}

Similar to HMI-I, other functionalized SBRs prepared by incorporating amino-methyl, -ethyl or - $\alpha$ - methyl styrene can be coupled very effectively by tin or silicon tetrachloride. However, as shown in Table 5, the coupling efficiency decreases with increasing amount of PES used for the co-polymerization. This is consistent with the fact that polymer coupling reaction is normally not very effective for polymerization catalyzed with highly modified (e.g., by tertiary amine) n-BuLi catalysts.

Table 5. Tin coupled pyrrolidine functional $20 / 80 \mathrm{SBRs}$ containing 0.25 to $5 \% \mathrm{PES}$ with $0.25 / 1 \mathrm{SnCl}_{4} / \mathrm{n}$-BuLi at $70{ }^{\circ} \mathrm{C}$.

\begin{tabular}{|c|c|c|c|c|}
\hline$\%$ PES & Coupling agent & Base ML-4 & Coupled ML-4 & $\%$ Coupling \\
\hline 0.25 & $\mathrm{SnCl}_{4}$ & 25 & 106 & 80 \\
\hline 0.5 & $\mathrm{SnCl}_{4}$ & 19 & 95 & 77 \\
\hline 1 & $\mathrm{SnCl}_{4}$ & 16 & 86 & 75 \\
\hline 2 & $\mathrm{SnCl}_{4}$ & 17 & 81 & na \\
\hline 5 & $\mathrm{SnCl}_{4}$ & 25 & 64 & na \\
\hline
\end{tabular}

Also, it was found the coupling efficiency was very similar for PAMS functionalized SBRs as compared with those of PES polymers (Table 6).

Table 6. Comparison of the coupling efficiency of PES and PAMS Functionalized 20/80 SBRs with $\mathrm{SnCl}_{4}$ at $70{ }^{\circ} \mathrm{C}$.

\begin{tabular}{|c|c|c|c|c|c|}
\hline$\%$ PES & $\%$ PAMS & Coupling agent & Base ML-4 & Coupled ML-4 & Coupling \\
\hline 0.25 & & $\mathrm{SnCl}_{4}$ & 19 & 95 & 77 \\
\hline & 0.5 & $\mathrm{SnCl}_{4}$ & 17 & 90 & 74 \\
\hline
\end{tabular}

The GPC was used to determine the efficiency of coupling reaction, type of coupling and the distribution of the final reaction products. As shown in Fig. 13, a pyrrolidine functionalized 20/80 SBR containing 0.5\% of PAMS (or, a 0.5/19.5/80 PAMS/styrene/1,3-Bd terpolymer) was coupled with $\mathrm{SnCl} 4$ at the end of polymerization, resulting in a mixture of products containing $58 \%$ of 4 -arm coupled, $16 \% 2$-arm coupled and $26 \%$ uncoupled base polymer. The total amount of coupling was calculated to be roughly $74 \%$.

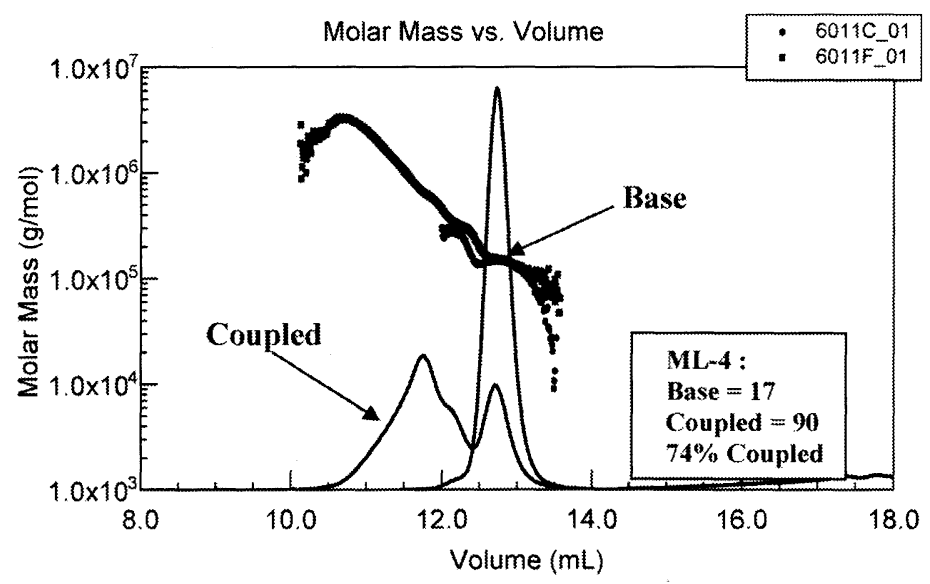

Figure. 13. GPC curve of a tin tetrachloride coupled pyrrolidine functionalized 20/80 SBR

The amount of incorporation of functional monomer into the polymer chain can be determined using NMR by measuring the percentage of protons or carbons which are closest (at the $\alpha$-position) to the nitrogen in the polymer. The chemical shifts of these protons and carbons are far away from those of all hydrocarbon portions of the polymer. As shown in Fig. 14, the amount PAMS in the polymer can be calculated by measuring the percentage of methylene carbons attached to nitrogen atom of the pyrrolidine ring at either 54.5 or $64.5 \mathrm{ppm}$. 


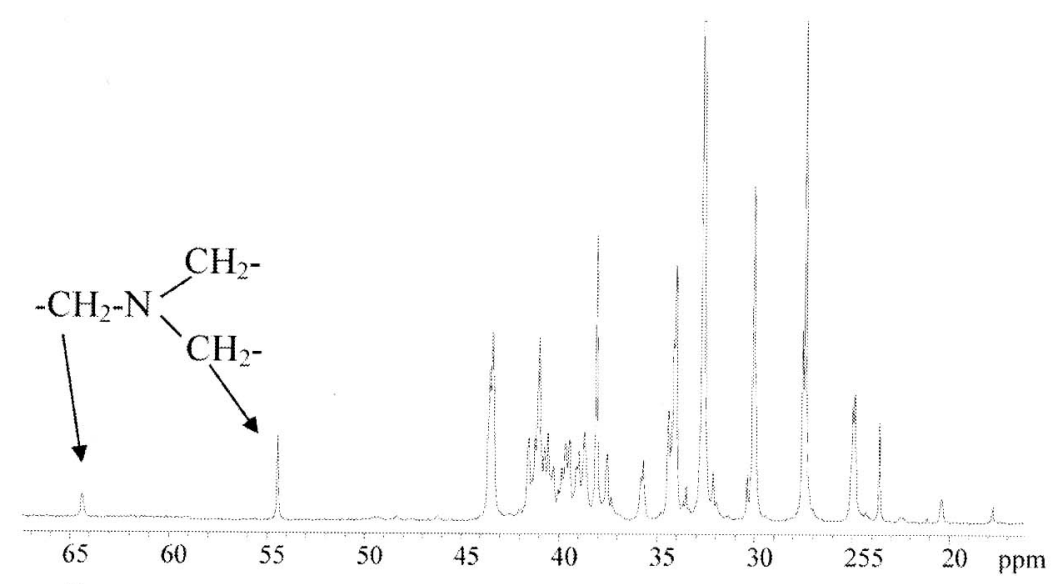

Figure $14 .{ }^{13} \mathrm{C}$ NMR spectrum of $5 / 95$ PAMS/Bd copolymer (5 wt \% polymer in $\mathrm{CDCl}_{3}$ solution)

As demonstrated so far, all amine functionalized styrene monomers discussed in this work exhibited similar polymerization rates as styrene under normal living anionic polymerization conditions and thus, they can be easily incorporated into the backbone of SBR (in-chain functionalization) at elevated temperatures ( 70 to $1000 \mathrm{C}$ ) to functionalize SBR. This in-chain functionalization process can also be extended to functionalize other organolithium catalyzed homopolymers, copolymers or terpolymers of dienes (e.g., 1,3-butadiene, isoprene, 2.3-dimethyl-1,3-butadiene, etc) with or without vinyl aromatic monomers (e.g., styrene, $\alpha$-methyl styrene, t-butyl styrene, etc), such as polybutadiene, polyisoprene, IBR, SIR, SIBR. They can also be used to functionalize high trans SBR prepared by a catalyst system consisting of organolithium, barium alkoxide and trialkyl aluminum catalysts [51].

Also, similar to styryl lithium initiator, formed from reacting styrene with lithium, a functional styryl lithium initiator can be formed by reacting the amino functionalized styrene with an equivalent amount of n-BuLi. These functional initiators can be used to initiate diene/styrene copolymerization and thus place the functional group at the beginning of the propagating chain. These amine functional monomers can also be added to the polymer live end after full monomer conversion, which leads to the incorporation of one or more functional groups at the end of polymer chain. Telechelic ( $\alpha, \omega$-difunctionalized) polymers containing amine functional groups at both ends of polymers can also be produced by combining both methods. Furthermore, if more functional groups are needed, one can always premix the functional monomers with diene/styrene monomers in addition to employing both methods described above. In addition to the random distribution of functional groups along the polymer backbones, one can also place functional groups at different locations of the polymer chain via the controlled addition of functional monomers during polymerization.

The functional styrenic monomers described here can be very versatile for preparing functionalized tire elastomers. As illustrated in Scheme 3 , possibilities of making in-chain (1), front-end (2), terminal chainend (3), telechelic ( $\alpha$, $\omega$ - difunctionalization) (4) and multi-functionalization (5) are demonstrated.

(1)

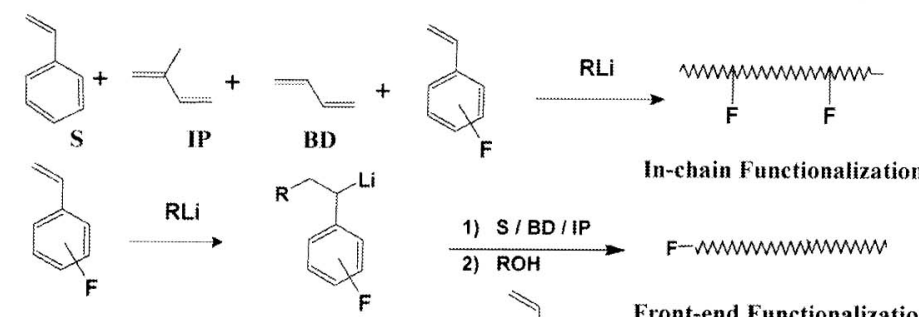

(3)

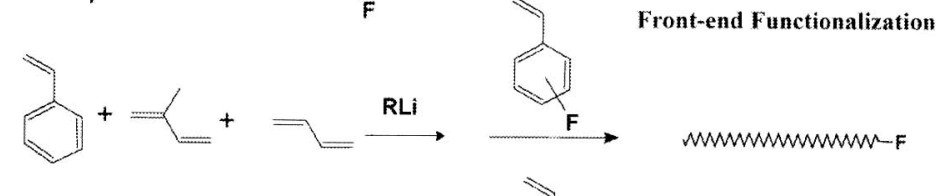

(4)

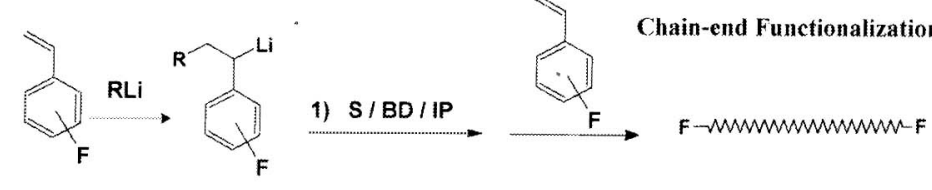

(5)
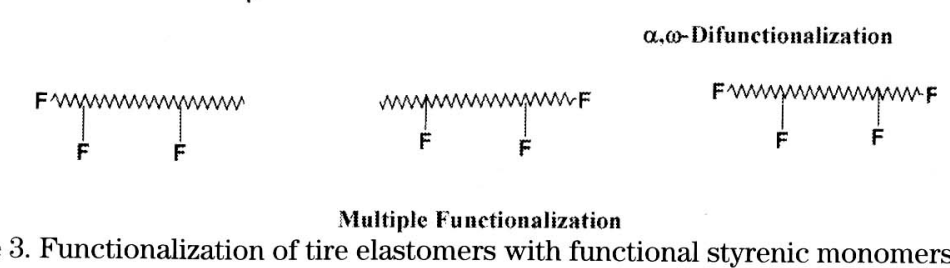

$\alpha, \omega-$ Difunctionalization

Scheme 3. Functionalization of tire elastomers with functional styrenic monomers

Although it is well known in the literature that tertiary amine containing functional groups are beneficial in promoting polymer-carbon black interaction $[4,8,15,28]$, other polar functional groups $[10,11,31,35,66]$, such as alkyoxylsilyl, expoxy, hydroxy, amide, esters, primary amine, $\ldots$ might even be more effective for improving the polymer - filler interaction for silica filled compounds. Numerous functional styrene monomers 
containing these functional groups have been developed by Hirao and coworkers [59]. They may offer potential benefits for silica filled compounds; however, most of them cannot coexist with n-BuLi. By protecting the polar functional groups from nucleophilic attack by n-BuLi, Hirao was able to conduct the anionic living polymerization with some of these polar functional styrene monomers [59]. As shown in Scheme 4, by incorporating the protected polar functional monomers into the polymer chain, in-chain functionalized polymers having potential for use in silica filled compounds may be prepared.

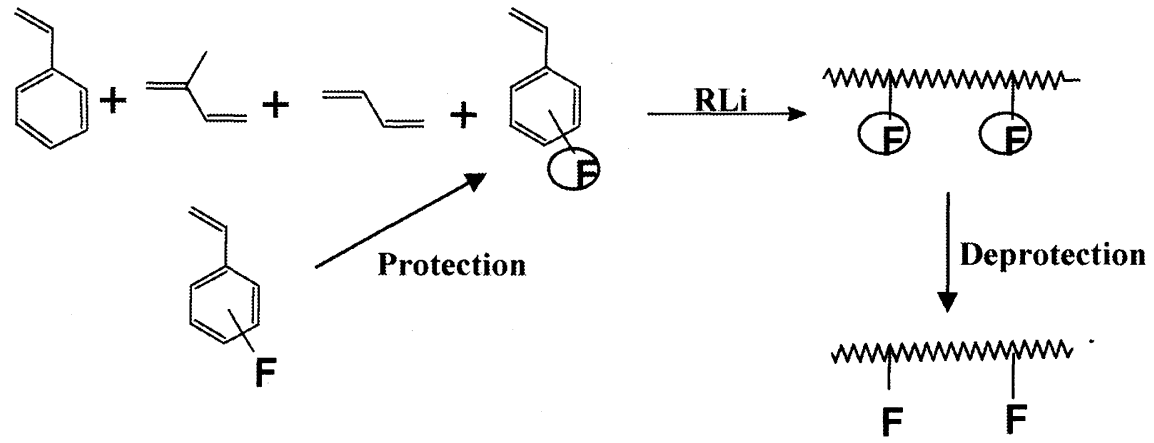

Scheme 4. In-chain functionalization using protected functional monomers

\section{Comments regarding possible branching reaction with PES functionalized polymers}

It was mentioned earlier that PES and PAMS were preferred over PMS due to suspected 1,6- elimination reaction for the latter, which might lead to polymer branching. However, branching reaction may occur for the PES and PAMS functionalized polymers as well but with different mechanism. As shown in Scheme 5, at high temperature, the reversed Michael addition might take place via hydride elimination from the benzylic proton of PES. This will kick the pyrrolidine off and generate a vinyl group which will react readily with live polymer chain end and cause polymer branching. This hydride elimination and the subsequent branching reaction may occur in the continuous process at high temperatures and may also take place in the batch polymerization if prolonged heating of the polymerization mixture is allowed after polymerization was completed. Since the polymerization rate is much faster than the possible hydride elimination, the best way to prevent the branching reaction is to shortstop the living polymer chains, right after the polymerization was completed, with coupling agent (e.g. SnCl4), functional terminating agents or a proton source.

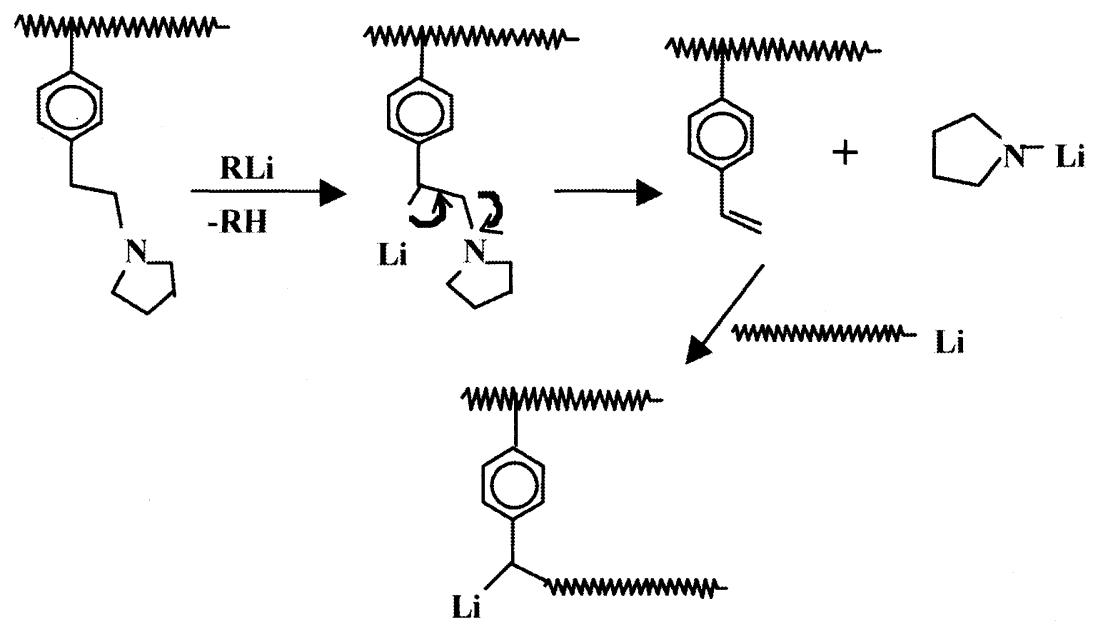

Scheme 5. Possible branching mechanism for PES functionalized polymers

\section{Compound Studies}

\section{Carbon black filled compounds}

To quantify the reduction in energy loss achievable through chain-end functionalization, a series of linear solution SBRs were synthesized having identical microstructure and narrow molecular weight distribution. The first series of polymers were initiated with n-BuLi and were terminated with ethanol, and therefore contained no functional groups. A second series of monofunctional polymers were prepared in which synthesis was initiated using 3-pyrrolidino-propyllithium (AI-205 from FMC Lithium). A third series of difunctional polymers included both pyrrolidine initiation and termination by a tin coupling agent. In each series, the molecular weight of the linear polymer was systematically varied, ranging from 100,000 to $200,000 \mathrm{~g} / \mathrm{mole}$, prior to any coupling reactions. 


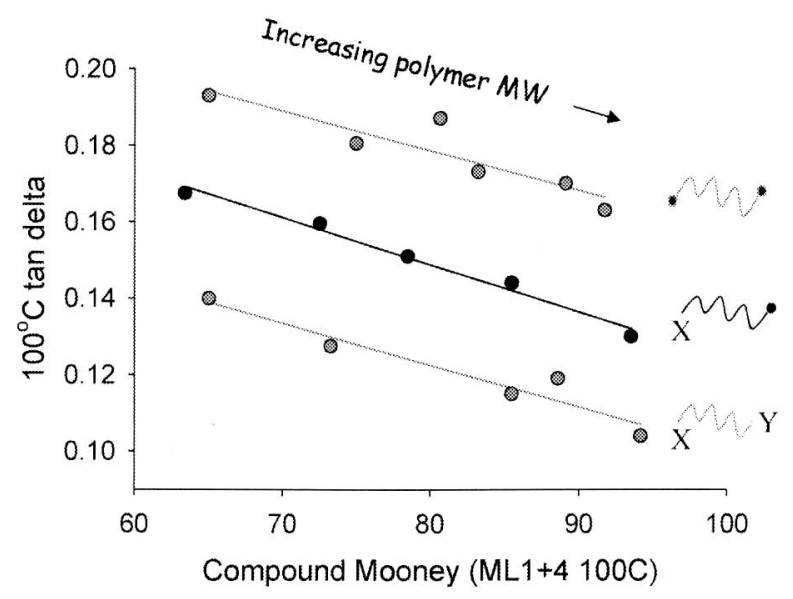

Figure 15. Effect of chemical functionality on hysteresis and processability

Each polymer was compounded into a passenger tire tread recipe reinforced with 55 phr of N299 carbon black. The balance achieved between processability and hysteresis for each type of SSBR is pictured in Figure 15. Each line in this figure represents the effect of polymer molecular weight on cured $\tan \delta$ (yaxis) and uncured compound viscosity (x-axis). To a first approximation, the Mooney viscosity of the green compound is an indicator of factory processability. If compound Mooney becomes too high it cannot be mixed and shaped in production at reasonable processing temperatures. Figure 15 indicates that a linear relationship exists between compound viscosity and tan $\delta$ for each type of polymer. Increasing the molecular weight of the polymer in all cases will reduce energy loss, but also causes an undesirable increase in compound viscosity. Using 80 ML-4 as an upper limit for viscosity, the three polymers can be fairly compared under conditions of similar factory processability, as shown in Figure 16.

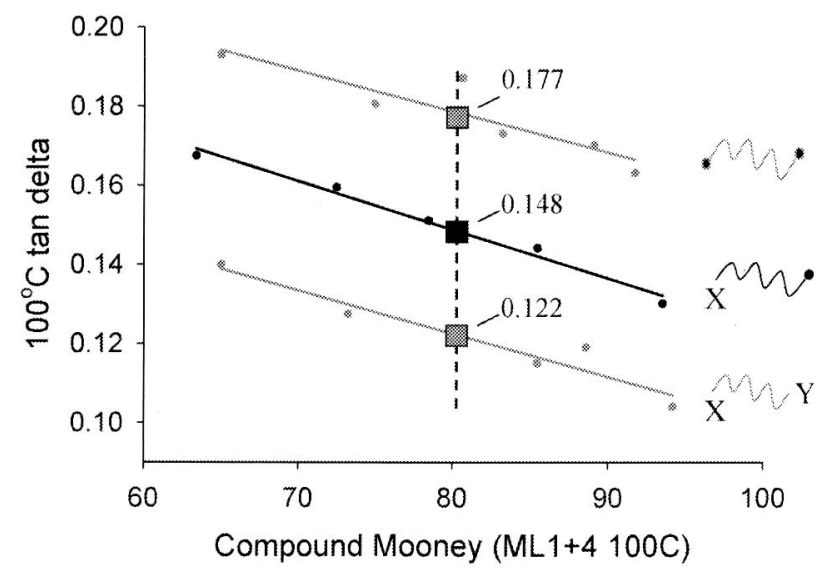

Figure 16. Procedure for comparing polymers at equivalent processing

Adding one pyrrolidine group to the terminal end of the SSBR chain provides a $16 \%$ reduction in energy loss, as tan delta decreases from 0.177 to 0.148 . Adding a second group to the remaining chain end results in another $15 \%$ decrease, reducing tan delta to 0.122 . This is expressed schematically in Figure 17. In this figure tan delta is observed to decrease linearly when expressed in terms of the number of functional groups contained within the polymer. If two functional groups per chain can reduce energy loss over $30 \%$, will additional functional groups reduce energy loss even further?

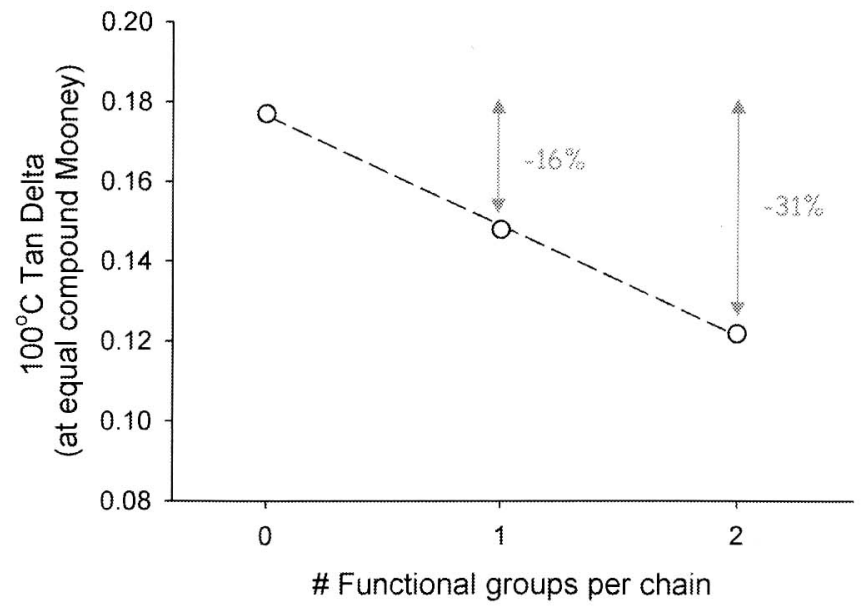

Figure 17. Effect of end-group concentration on hysteresis 
Using functional co-monomer technology, a higher concentration of functional groups per chain can be readily obtained. The ability of functional co-monomers to reduce energy loss was explored using the same passenger tread recipe ( 55 phr carbon black) and the same evaluation procedures outlined above. Figure 18 displays the performance of seven different types of functional monomers, at concentrations ranging from 3 to 40 functional groups per SSBR chain.

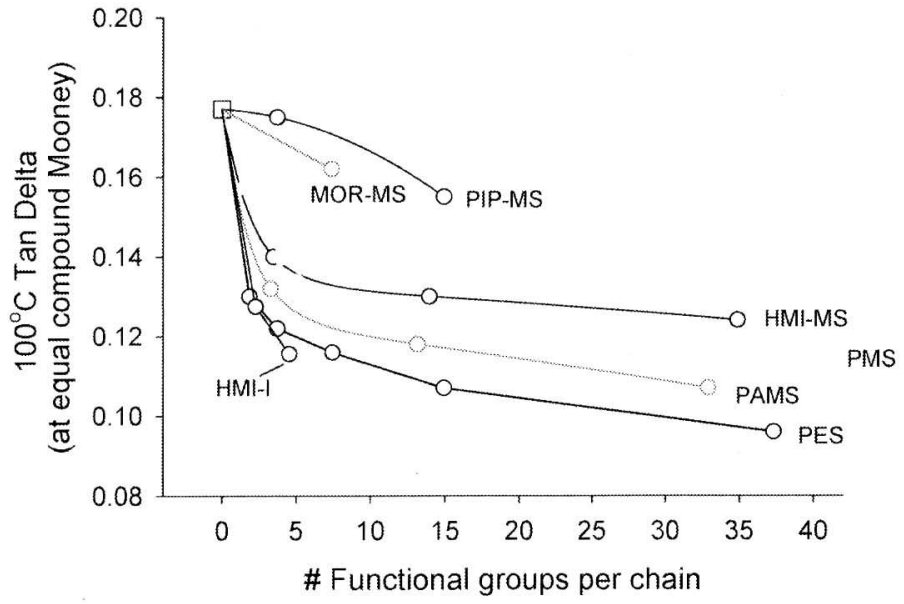

Figure 18. Concentration effects using functional monomers

The number of functional groups per chain was calculated based upon the amount of functional monomer charged into the polymerization reactor and the number-average molecular weight of the polymer, assuming no side reactions take place. The figure reveals a tremendous difference in the ability of the functional monomers to reduce the energy loss of the tread compound. While the piperidine-MS (PIP-MS) and morpholine-MS (MORMS) groups were only weakly effective, the PES and HMI-I were very effective. Even at concentrations as low as 2 functional groups per chain, the PES and HMI-I monomers reduce tan delta to an extent similar to the end-functional polymers described previously. Based upon its high CB interaction and the relative ease of monomer preparation, the PES monomer was chosen for continued investigation.

The results indicate that most of the benefit PES provides in carbon black-filled compounds takes place at very low levels of functionalization. Above 5 functional groups per chain tan delta continues to decrease, but at a marginal rate. The PES groups reduce energy loss by attaching the polymer to the $\mathrm{CB}$ filler, providing a means to improve the distribution of the filler during mixing and to reduce its tendency to coalesce into networks during vulcanization. Once the filler network is eliminated, the addition of more functional groups to the chain provides only small improvement.

Similarly, the primary benefit of chain-end functionalization is a reduction in filler-filler networking. At the same time, directing the polymerfiller attachment point to the end of the polymer can, in theory, eliminate the contribution of dangling chain ends to energy loss and further reduce hysteresis. A comparison of the efficiency of chain-end and random functionalization with PES is given in Figure 19.

The difference in the efficiency of the two functionalization methods is surprisingly very small. In order to reduce compound hysteresis by $30 \%$, two functional groups are required in the end-functional polymer (both ends), while the randomly functionalized polymer requires four. The attractive feature of the random polymerization process is that functional group concentration is easily adjustable. It is clear that random functionalization with PES can meet or exceed the performance of end-functionalization technology.

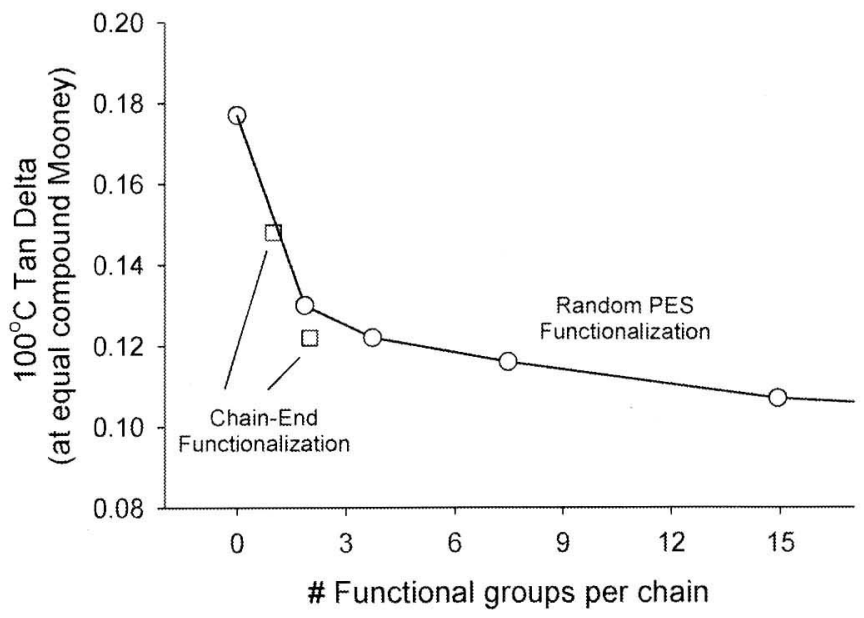

Figure 19. Chain-end vs. random functionalization

To demonstrate the ability of the PES monomer to reduce carbon black networking and flocculation, a PES-functional SSBR having an average of four functional groups per chain was compounded into the CBfilled tread recipe shown in Table 7. A nonfunctional SSBR having the same styrene and vinyl content was used as a control, crosslinked to the same ultimate tensile elongation. 
Table 7. Carbon Black Networking Recipes

\begin{tabular}{l|cc}
\multicolumn{1}{c|}{ Ingredient } & $\begin{array}{c}\text { Nonfunctional } \\
\text { SSBR (phr) }\end{array}$ & $\begin{array}{c}\text { PES-SSBR } \\
\text { (phr) }\end{array}$ \\
\hline Polymer & 100 & 100 \\
ISAF Tread Back & 70 & 70 \\
Aromatic Oil & 38.5 & 38.5 \\
Zinc Oxide & 2.5 & 2.5 \\
Stearic Acid & 3 & 3 \\
Sulfur & 2.0 & 1.6 \\
CBS Accelerator & 1.2 & 1.0 \\
TMTD Accelerator & 0.25 & 0.20
\end{tabular}

A plot of dynamic modulus as a function of strain for each of these compounds is shown in Figure 20. At very low strains, dynamic modulus is influenced by both the polymer network and the filler-filler network. Under these conditions $(0.1 \%$ strain) the modulus of the nonfunctional polymer is nearly twice that of its PES-functional counterpart. On the other hand, at high strains when the filler network is fragmented, the two compounds are equivalent in modulus. This dependence of modulus on strain level is frequently observed in filled compounds, and is known as the Payne Effect.

Functional polymers (both random and end-functionalized versions) improve rolling resistance by reducing filler networking, which is the leading cause of low frequency energy loss in the tire tread [67]. However, these functional polymers behave similar to nonfunctional polymers of the same $\mathrm{Tg}$ at lower test temperatures or high frequency deformation. For this reason, functional polymers can improve a tread's RR with no sacrifice in the tread's wet traction properties. A plot of tangent delta as a function of temperature is shown in Figure 21. In this case a PES-functional SIBR polymer is compared to a nonfunctional SIBR of identical $\mathrm{Tg}$. At $60^{\circ} \mathrm{C}$, the polymer containing PES is clearly less hysteretic, but at temperatures below $0{ }^{\circ} \mathrm{C}$ the PES polymer is at least as dissipative as its nonfunctional counterpart.

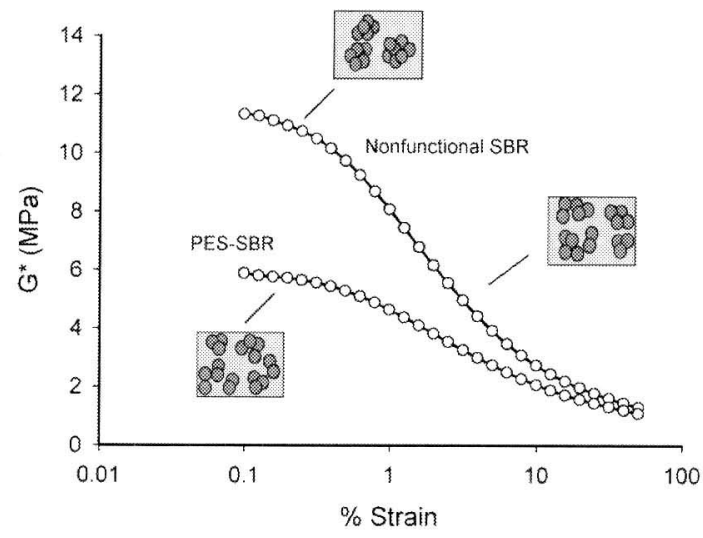

Figure 20. Filler-filler networking reduction in PES-functional SBR

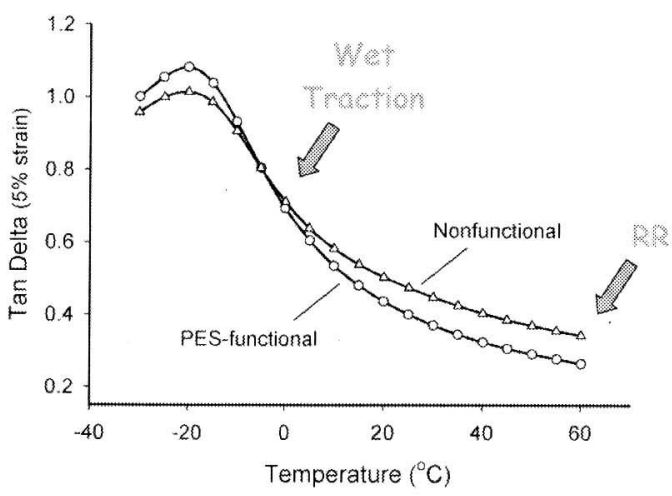

Figure 21. Effect of temperature on energy loss behavior

\section{Silica filled compounds}

When silica filler is used to reinforce a tire compound, the difference in surface energy between filler and polymer is large, much greater than the difference between polymer and carbon black. As a result, the filler-filler networking is even more pronounced in silica-filled compounds. To resolve this, today's compounding approach is to use a combination of wetting and coupling agents to improve the affinity between the polymer and the silica filler. Low molecular weight polar additives such as glycols and amines facilitate dispersion by adsorbing onto the surface of silica thereby reducing its surface energy. Silane coupling agents such as bis-(3-triethoxysilylpropyl) tetrasulfide (TESPT) include sites which bond to the silica during mixing as well as sites which chemically bond to the polymer during vulcanization. Both approaches are an effective means of reducing filler-filler networking and hysteresis in silica-filled tire compounds. 
Polymers having pendant amine groups are uniquely capable of interacting directly with silica, and do not require the high levels of wetting and coupling agents normally implemented. To study the ability of PES-functional SSBR polymers to reduce hysteresis in silica-filled treads, compounds were prepared using $55 \mathrm{phr}$ of a highly dispersible silica with no additional wetting or coupling agents. Figure 22 shows the relationship between cured compound tangent delta and the average concentration of functional groups within the polymer chain. The dotted line in the figure represents the value of tangent delta obtained using a typical loading of TESPT coupling agent in the nonfunctional SSBR.

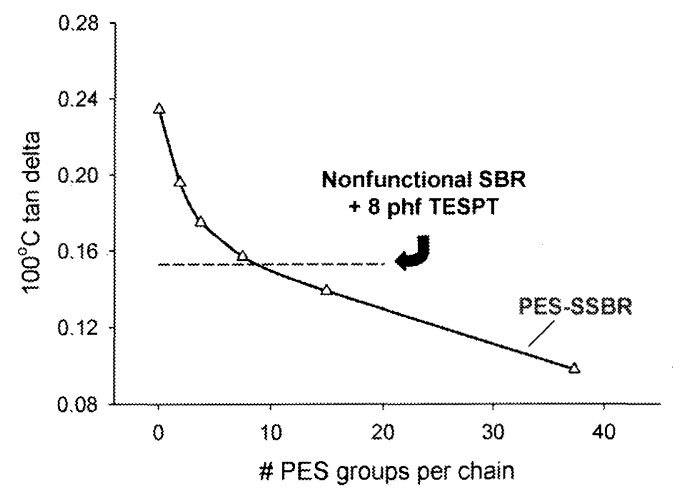

Figure 22. Effect of PES concentration on silica-filled energy loss

The nonfunctional SSBR exhibits a tan delta value of 0.24, which is even more energy loss than that observed when 55 phr of N299 carbon black is used (Figure 19). This is an indication of the extensive filler networking which takes place in untreated silica compounds. Energy losses drop rapidly when PES concentration is increased, especially at low functionalization levels. At a PES level of 10 groups per chain, the silane-free PES polymer is even more energy efficient than the nonfunctional polymer compounded with the normal compliment of silane coupling agent.

Compared to carbon black, untreated silica compounds require higher concentrations of PES functionality to achieve low rolling resistance. Figure 19 shows that over $90 \%$ of the tan delta benefit is obtained using as little as four functional groups per chain. In contrast, significant improvements in hysteresis are observed in silica formulations using as many as 35 functional groups per chain.

\section{Conclusions}

Styrenic and $\alpha$-methyl styrenic monomers containing various cyclic amines can be prepared in good yields from divinylbenzene and diisopropenyl benzene respectively. They can be randomly co-polymerized with conjugated dienes and vinyl aromatic monomers to form in-chain amine functionalized tire elastomers at elevated temperatures. Although the copolymerization of these functional monomers can be conducted in a continuous process, polymer branching may occur due to chain transfer reaction which likely result from elimination and addition cycles taking place at elevated temperatures. Prolonged heating in the batch process at high temperatures may also produce branched polymers.

The in-chain pyrrolidine functionalized polymers interact strongly with carbon black and/or silica fillers and greatly reduce the Payne effect and hysteresis of the resulting rubber compounds. In carbon black compounds, although they provide similar or slightly better hysteresis reduction than chain-end functionalized telechelic polymers, the in-chain functionalization may represent a simpler and perhaps a more economic alternative to the conventional $\alpha, \omega$-difunctionalization process. In untreated silica compounds, a higher concentration of the functional monomer is needed to both wet the silica and reduce hysteresis.

\section{Acknowledgments}

The authors are grateful to The Goodyear Tire \& Rubber Co. for granting permission to publish this work. The authors are indebted to Denny Werstler for the NMR work and other colleagues at the Goodyear Tire \& Rubber Co. for their dedicated efforts to this work.

\section{References}

(1) A Bond, G F Morton and L H Krol, Polymer, 25, 132 (1984)

(2) D J Schuring and S Futamura, Rubber Chem. and Technol., 63, 315 (1990)

(3) A Ueda, H Watanbe and S Akita, Proc. Int. Rubber Conf., Kyoto, Japan 199 (1985)

(4) N Nagata, T Kobatake, H Watanbe, A Ueda and A Yoshioka, Rubber Chem. and Technol., 87, 837(1987)

(5) T Fujimaki, M Ogawa, S Yamaguchi, S Tomita and M Okuyama, Proc. Int. Rubber Conf., Kyoto, Japan 184 (1985)

(6) F Tsutsumi, M Sakakibara and N Oshima, Rubber Chem. and Tech., 63(1), 8 (1990)

(7) R P Quirk, J yin, S Guo, X Hu, G J Summers, J Kim, L Zhu, J Ma, T Takazawa and T Lynch, Rubber Chem. and Technol., 64, 648 (1991)

(8) D F Lawson, D R Brumbaugh, M L Stayer, J R Schreffler, T A Antkowiak, D Saffles, K Morita and S Nakayama, Polymer Preprint, 37(2) 728, 1996.

(9) J M Hall, D F Lawson and T A Antkowiak (to Bridgestone Corp.), EP0693505 (Jan. 24, 1996)

(10) I Furuta and I Hattori, Presented at Rubber Div., ACS., Nashville, Tenn., Paper \# 103, Nov. 3 (1992)

(11) A Saito, H Yamada, T Marsuda, N Kubo and N Ishimura, Presented at Rubber Div., ACS., Savannah, Georgia, Paper \# 39 , April 29 (2002)

(12) W L Hergenrother (to Bridgestone Corp.) EP0890587 (Jan. 13, 1999) 
(13) M Hayashi, Macromol. Symp. 215, 29 (2004)

(14) T Fujimaki and K Marita, Int. Polym. Sci. and Technol., 2(2) T/26 (1999) ant references therin.

(15) D Lawson, et al., ACS Rubber Div. Mtg., Presented at Rubber Div., ACS, Indianapolis, Indiana, May 5 (1998)

(16) A R Payne, Rubber Chem. and Technol., 36, 147 (1963)

(17) T Bethea, Rubber \& Plastics News, August 29 (1994)

(18). A F Halasa, B A Matrana and S E Robertson-Wilcox (to Goodyear Tire \& Rubber Co.), US 4,935,471 (June 19,1990)

(19) R P Quirk, S H Jang and J Kim, Rubber Chem. and Technol., 69, 4445 (1996)

(20) R P Quirk, S H Jang, H Yang and Y Lee, Macromol. Symp., 132, 281 (1998)

(21) D E Sutton and J A Schwindeman in "Modern Synthetic Methods and Novel Structure". A O Paitil, A N Schulz and B M Novak, Ed., ACS Symposium Series No. 174, 58 (1997)

(22) D A Benko, K ABates and S K Henning, Paper\# 3A, ITEC, Akron OH, Sept. 10, 2002

(23) L H Tung, G Y-S Lo and D E Beyer (to Dow Chemical Co.), US 4,196,154 (Apr. 1, 1980)

(24) K Bronstert (to BASF Aktiengellscharft), US 4,861,742 (Aug. 29, 1989)

(25) R P Quirk and J J Ma, Polym international 24, 197 (1991)

(26) W L Hsu and A F Halasa (to Goodyear Tire \& Rubber Co.) US 6,686,504 (Feb. 3, 2004)

(27) Y S Yu, Ph Dubois, R Jerome and Ph Teyssie, Macromolecules 29, 2738 (1996)

(28) D F Graves, Tire Technology International Annual Review, 10 (2003)

(29) R Rauline (to Michelin), US 5,227,425 (July 13, 1993)

(30) E H Tan, S Wolff, M Haddeman, H P Grewatta and M J Wang, Rubber Chem. and Technol., 66, 594 (1993)

(31) S Wolff, Kautsch. Gummi Kunstst. 34, 280 (1981)

(32) S Wolff, Rubber Chem. and Technol., 69, 325 (1996)

(33) V M Monroy, S D Hofmann and R Tietz, Presented at Rubber Div., ACS., Cleveland, Ohio, Paper \# 63A, Oct. 16, (2001)

(34) M Nakamura and Y Takagishi, Presented at Rubber Div., ACS., Dallas, Texas, Paper \# 30, April 4,

(35) Shimizu, Takashi, and Hachioji-shi (to Bridgestone Crop.) EP0773231 (May 14, 1997)

(36) M P Wagner, Rubber Chem. and Tech., 49, 703 (1976)

(37) K Yanagisawa, Presented at Rubber Div., ACS., Pittsburgh, Pennsylvania, Paper \# 69, Oct. 8 (2002)

(38) G Cameron, et. al., Makromol. Chem., Rapid Commum. 2, 287 (1981)

(39) Guo et. al., Macromol. 23, 5047 (1990)

(40) W L Hsu and A F Halasa (to Goodyear Tire \& Rubber Co.) US 5,652,310 (July 29,1997)

(41) T Scholl, U Elsele, J Trimbach (to Bayer Aktiengesellschaft), US 6,252,008 (June 26, 2001)

(42) T Scholl and J Trimbach and S Kelbch (to Bayer Aktiengesellschaft), US 6,365,668 (June 26, 2001)

(43) T S Toshiki (to Bridestone Corp.) JP1995082422A (March 28, 1995)

(44) C Petzhold, R Morschhauser, H Kolshorn and R Stadler, J Macromolecules 27, 3707 (1994)

(45) L A Rusch-Salazar, M K Rath-Murphy and V Sheares, Polymer Peprint, 43(1), 723 (2002).0

(46) V Shears (to Iowa State Univ.) US 6,344,538 (Feb. 5, 2002) and US 6,100,373 (Aug. 8, 2000)

(47) W.L.Hsu, A.F. Halasa and T. T. Wetli, Rubber Chem. \& Tech., 71, 62 (1997)

(48) H. Gilman and F.K. Cartledge, J. Organomet. Chem., 2, 447 (1964).

(49) C.C. Chang, A.F. Halasa, and J.M. Miller, J. Appl. Polym. Sci., 47, 1589 (1993).

(50) L Wu, V V Sheares, J Polym Sci. Polym. Chem., 39(9), 3227 (2001)

(51) A F Halasa ,W L Hsu and N Ogata (to Goodyear Tire \& Rubber Co.) US 6,753,447 (June 22, 2004)

(52) J A Dalphond, S K Henning,C W Burkhart and S Rodewald, , Presented at Rubber Div., ACS., Paper\# 14, Columbus, OH, Oct. 5, 2004

(53) T Tsuruta and T Narita, Y Nitadori and T Irie, Makromol. Chem. 177, 3255, 1976

(54) Y Nitadori and T Tsuruta, Makromol. Chem. 180, 1877, 1979

(55) J Yukawa, K Kataoka, Y Nitadori and T Tsurta, Polymer J, 11(2), 163 (1979)

(56) C Petzhold, R Stadler and H Frauenrath, Makromol. Chem., Rapid Commun. 14, 33 (1993)

(57) R Bieringer and V Abetz, Polymer 41, 7981 (2000)

(58) A Hirao, Y Negishi, M Hayashi, K Sako, W Ryu, S Lokulnant, A Matsuo and K Sugiyama, Macromol. Chem. Phys., 202(18), 3590 (2001)

(59) A Hirao, S Loykulnant and T Ishizone, Prog. Polym. Sci., 27, 1399 (2002)

(60) K Se, Polym. Adv. Technol., 14, 177 (2003)

(61) N Hadjichristidis, S Pispas, H Iatrou and M Pitsikalis, Current Organic Chemistry, 6, 155 (2002)

(62) A F Halasa, L E Austin and S A Weakland (to Goodyear Tire \& Rubber Co.), US 5,623,035 (April 22. 1997) and US 5,629,256 (May 13, 1997)

(63) A F Halasa and S A Weakland, unpublished results.

(64) A F Halasa and W L Hsu, Polymer 43, 7111 (2003)

(65) S Futamura, Angew. Makromol. Chem. 240, 137, 1996.

(66) T Toshihiro, T Keisuke and K Naoichi (to JSR Corp.) JP2003171418 (June 20, 2003)

(67) J D Ulmer, W L Hergenrother and D F Lawson, Rubber Chem. \& Tech., 71, 637 (1997) 